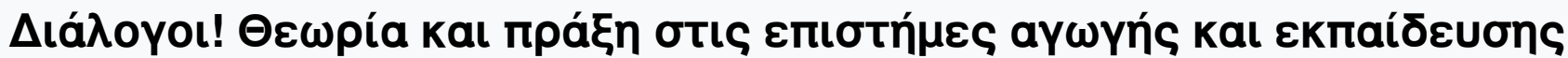

Tóp. 4 (2018)

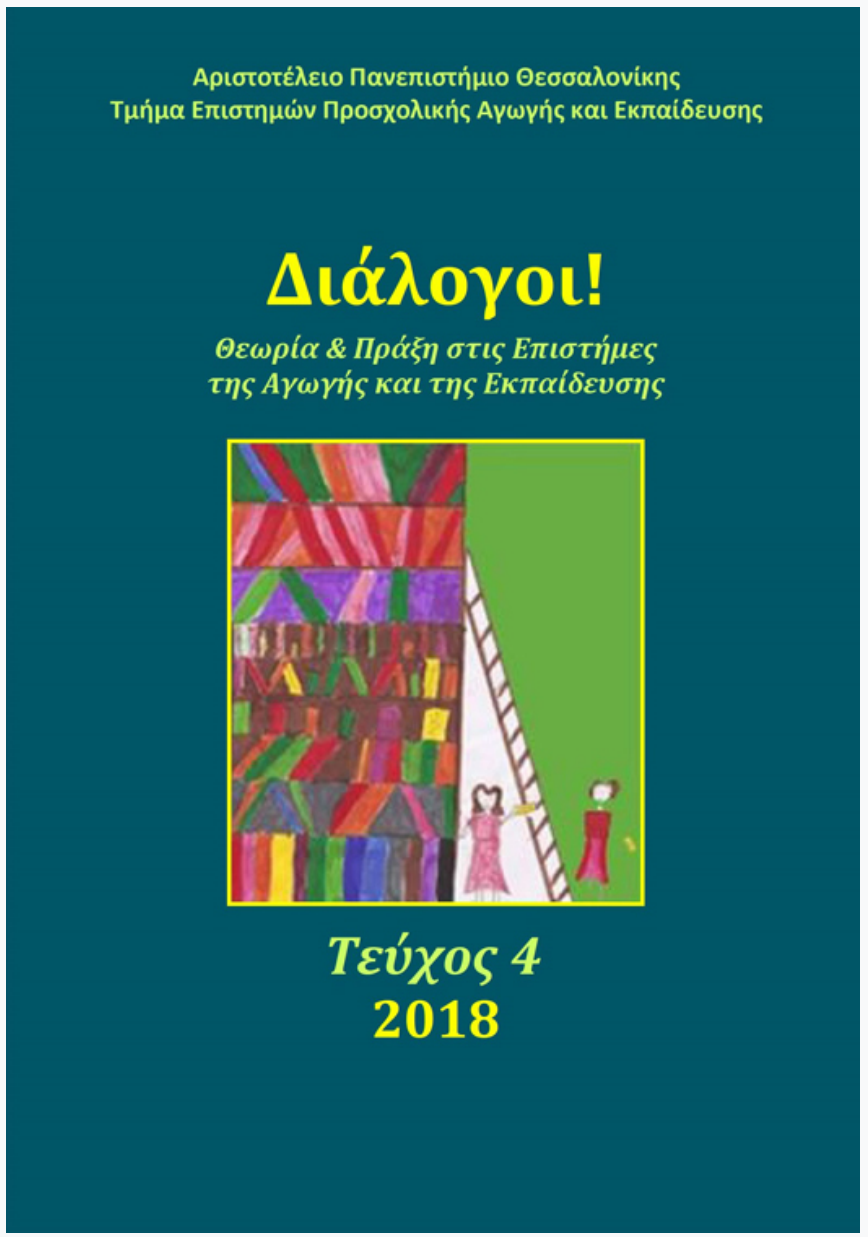

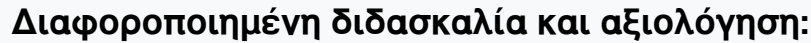

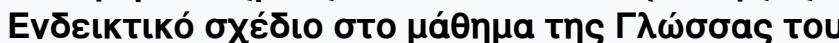

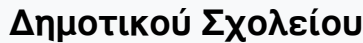

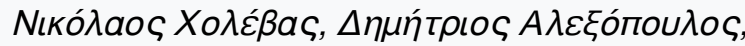

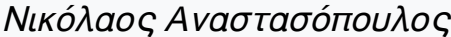

doi: $\underline{10.12681 / \text { dial.16126 }}$

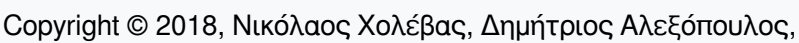

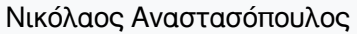

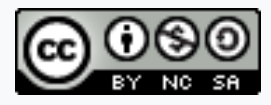

Ađฮsıa Xpńбnৎ Creative Commons Attribution-NonCommercial-ShareAlike 4.0.

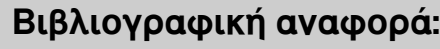

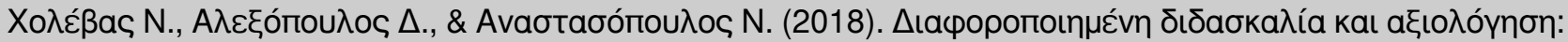

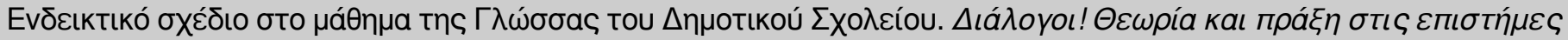

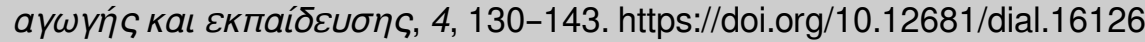




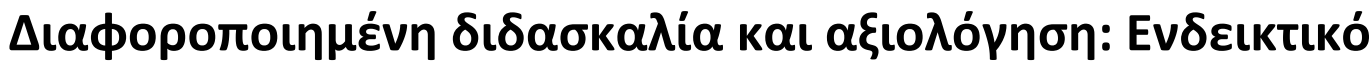

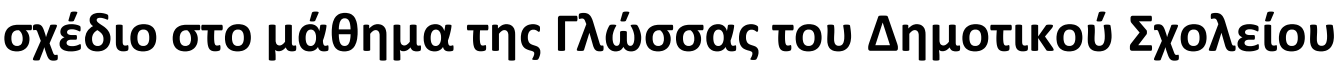

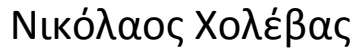

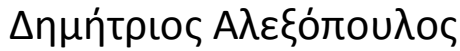

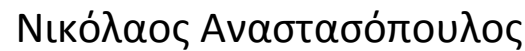

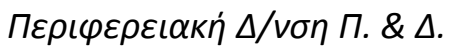

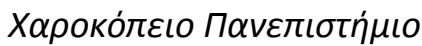

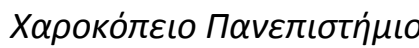

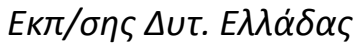

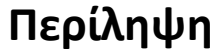

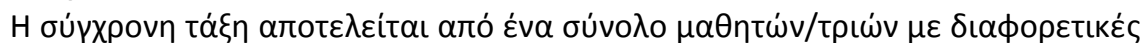

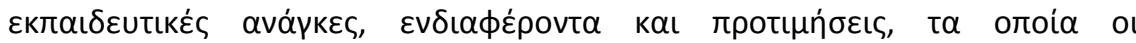

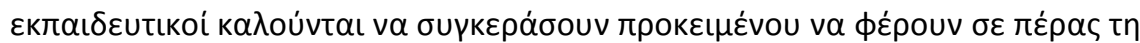

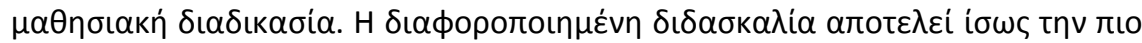

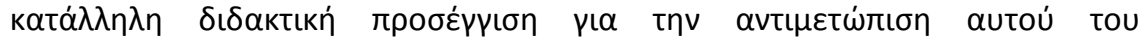

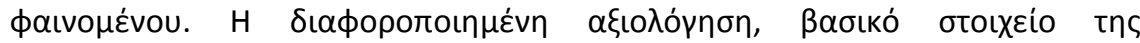

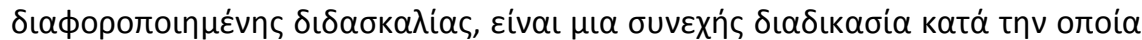

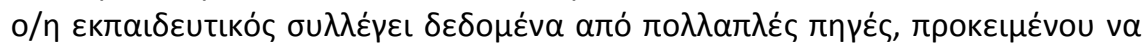

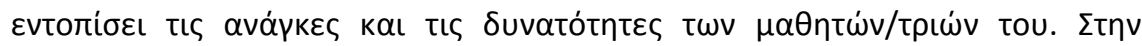

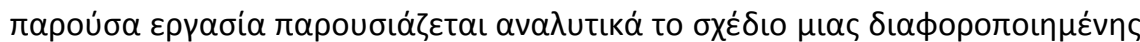

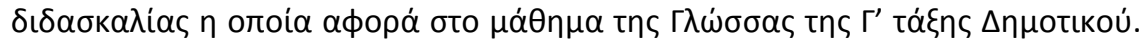

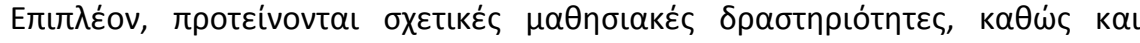

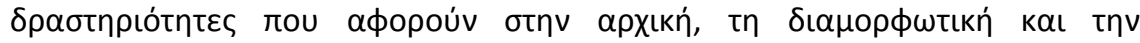

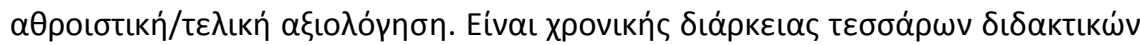

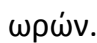

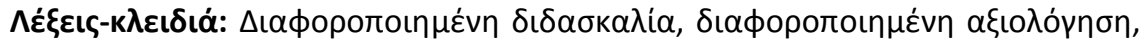

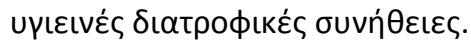

\begin{abstract}
The contemporary class includes students with different academic needs, interests and preferences, who teachers are called upon to bring together in order to complete the learning process. Differentiated instructionis, perhaps, the most appropriate teaching approach to addressing this phenomenon. Differentiated assessment, a key element of differentiated instruction, is a continuous process during which the teacher collects data from multiple sources in order to identify the needs and abilities of his/her pupils. In this paper, a differentiated lesson plan for the subject of Language of grade three of Primary School is presented in detail. In addition, relevant learning activities are proposed, as well as activities related to pre-assessment, formative and summative assessment. Properly-implemented assessment in all its forms plays a decisive role in the differentiation of instruction regarding pupils' differences in learning readiness, learning profile, interests, and inclinations. The above plan requires four teaching hours.
\end{abstract}

Keywords: Differentiated instruction, differentiated assessment, healthy eating habits.

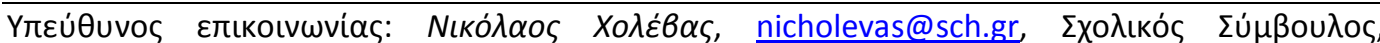

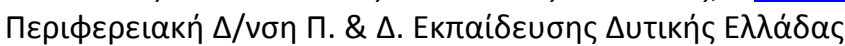




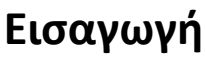

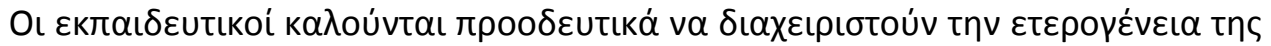

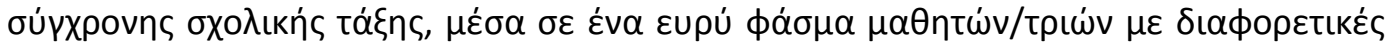

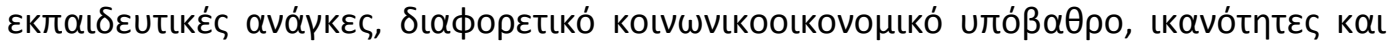

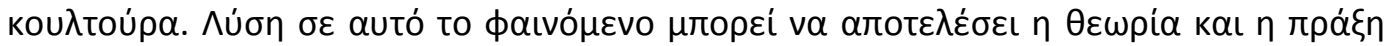

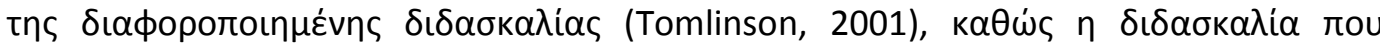

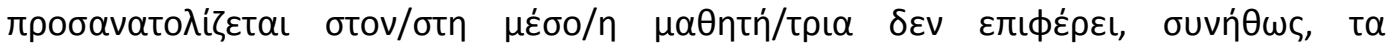

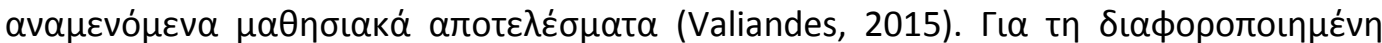

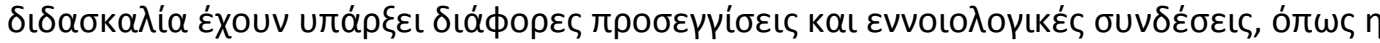

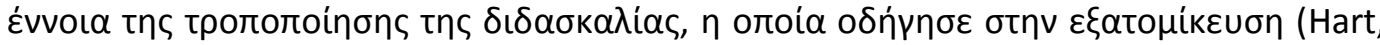

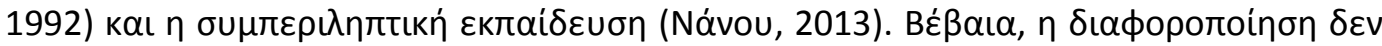
a

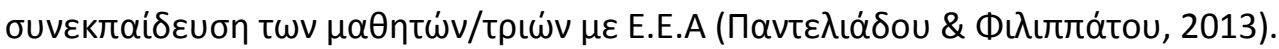

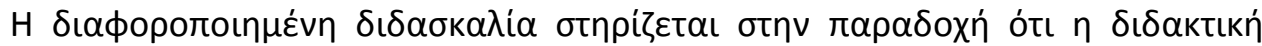

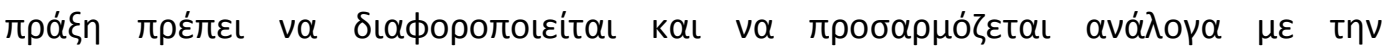

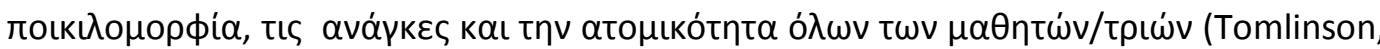

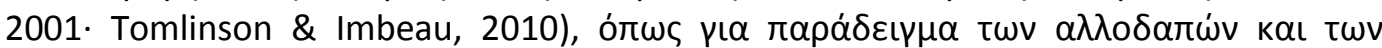

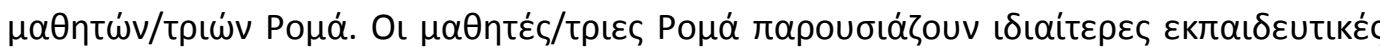

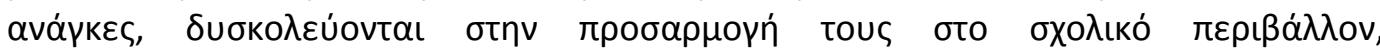

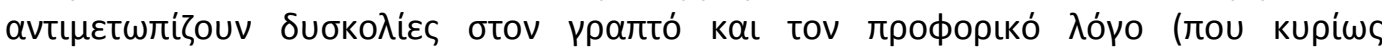

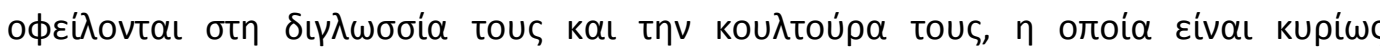

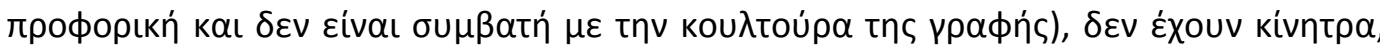

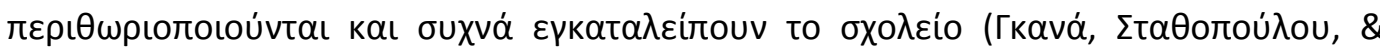

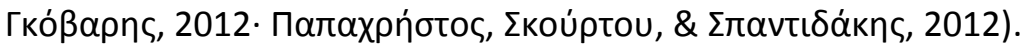

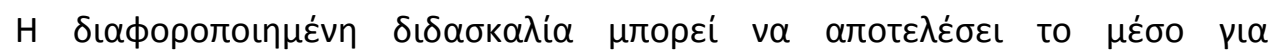

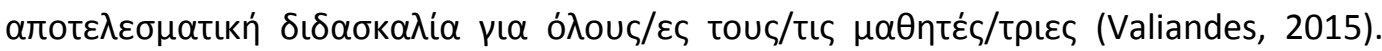

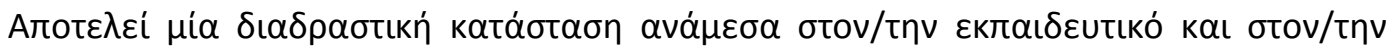

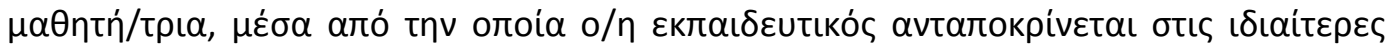

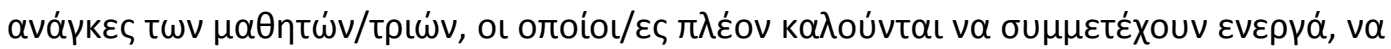

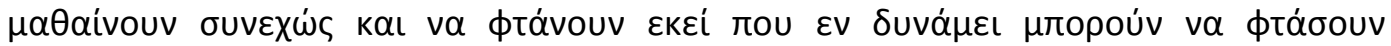

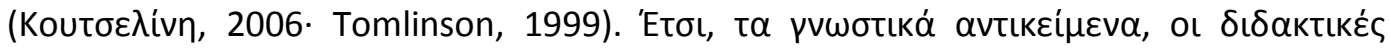

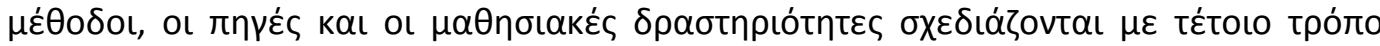

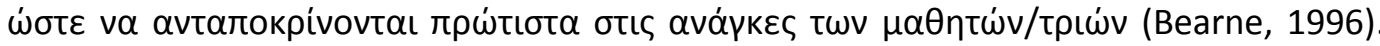

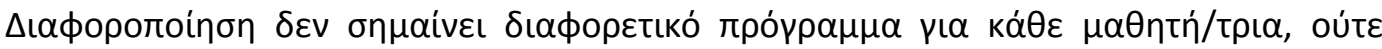

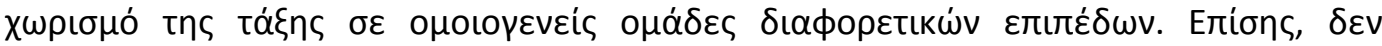

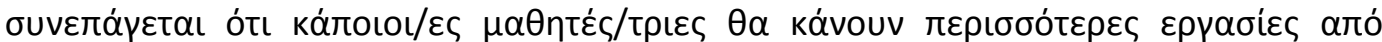

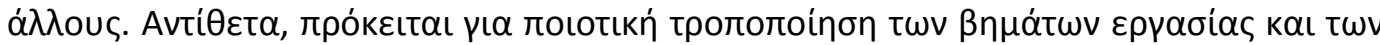

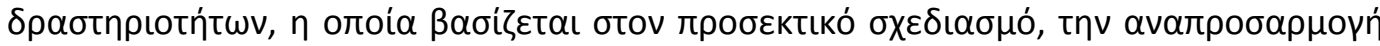

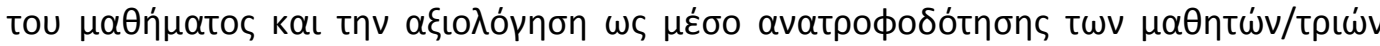

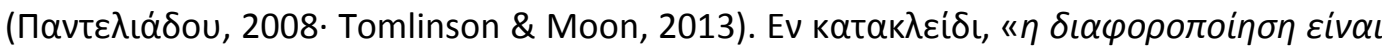

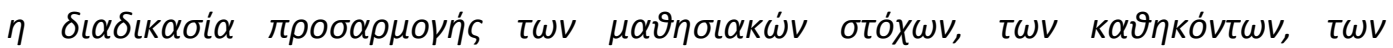

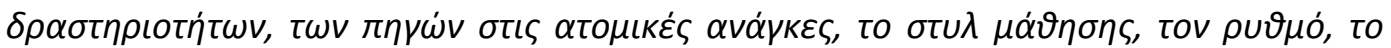

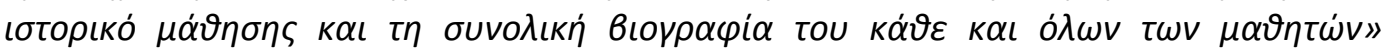

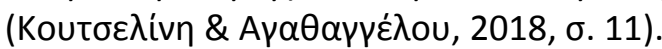




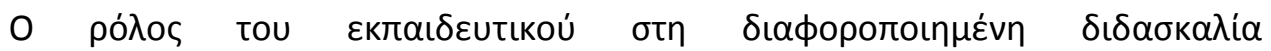

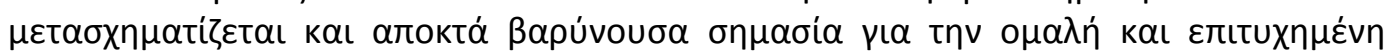

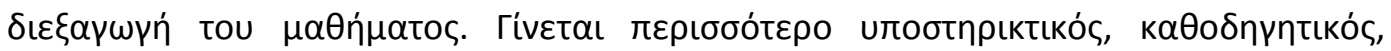

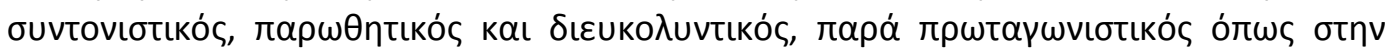

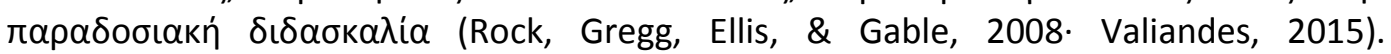

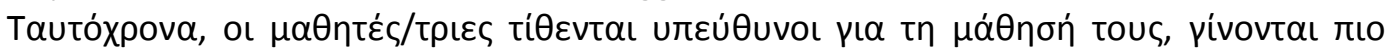

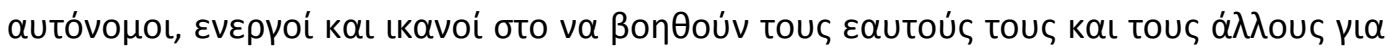

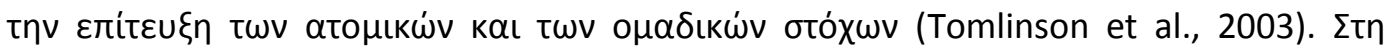

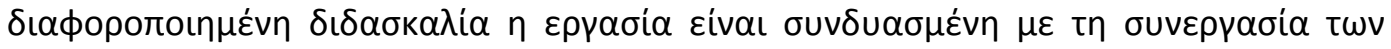

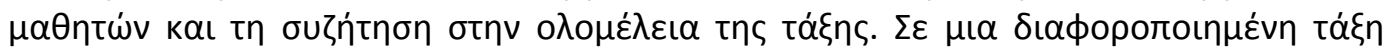

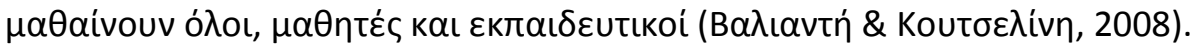

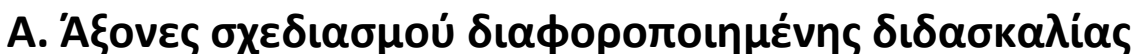

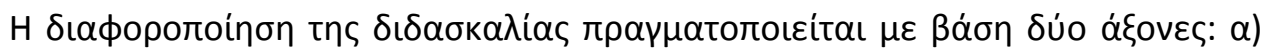

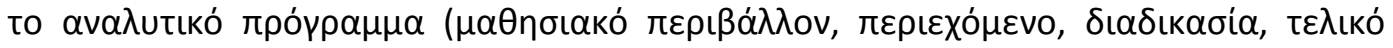

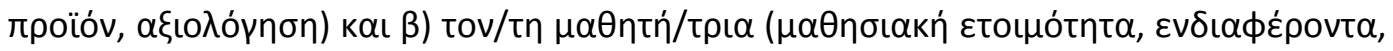

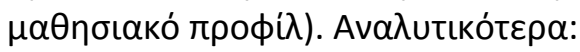

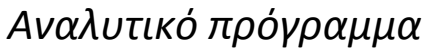

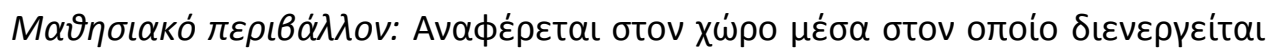

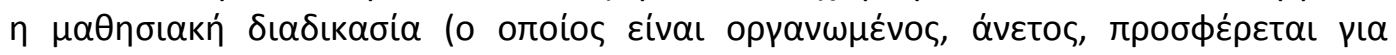

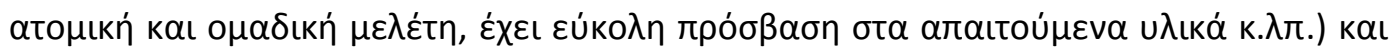

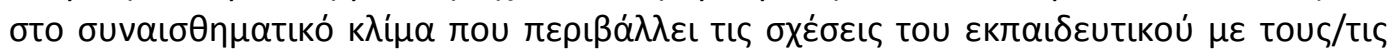

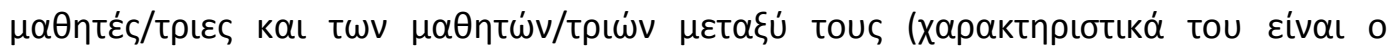

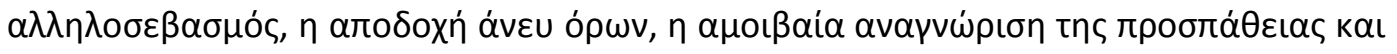

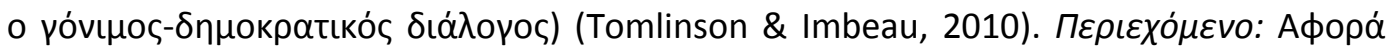

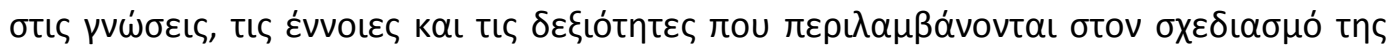

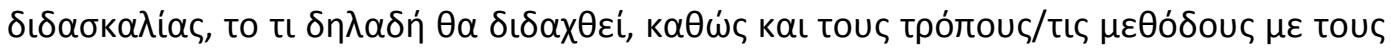

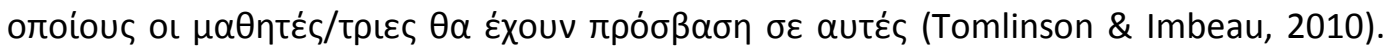

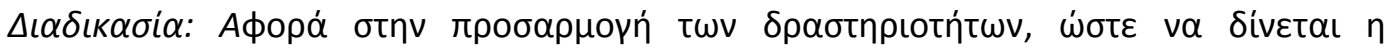

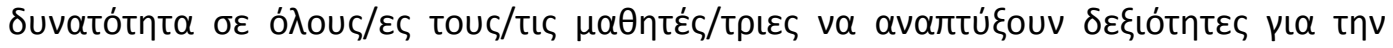

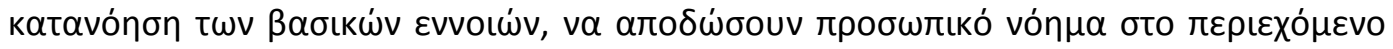

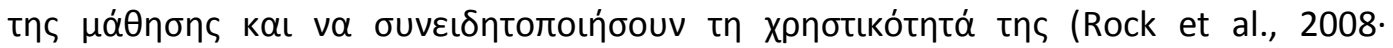

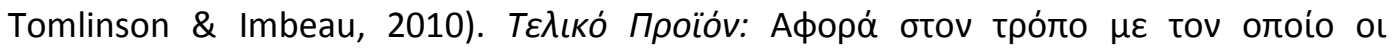

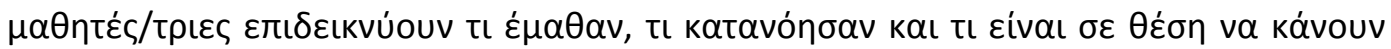

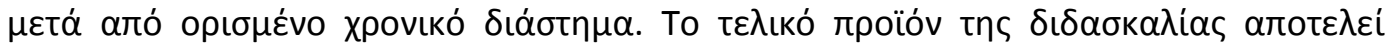

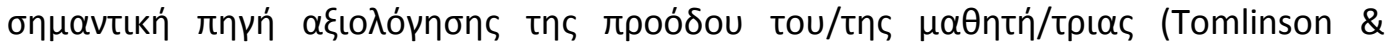

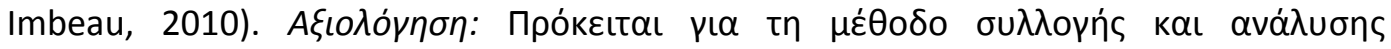

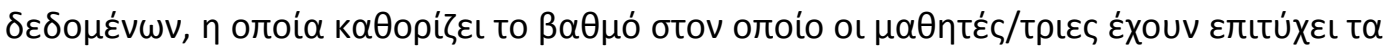

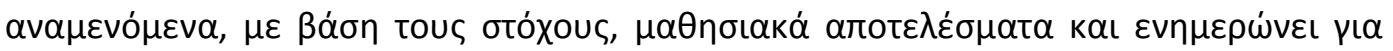

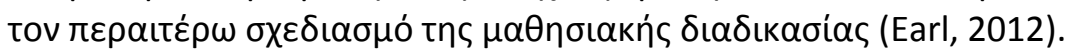

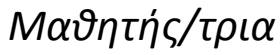

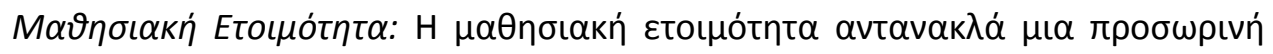

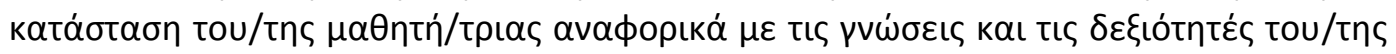

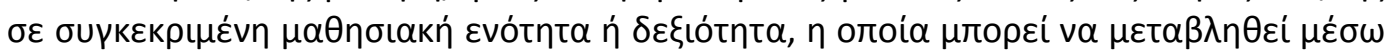




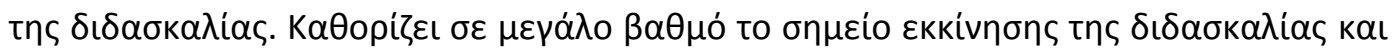

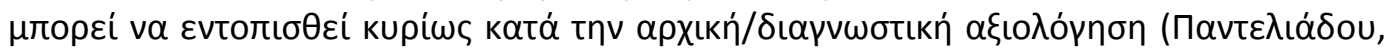

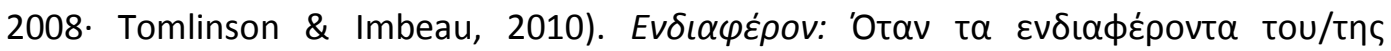

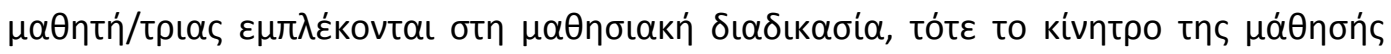

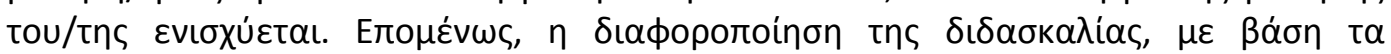

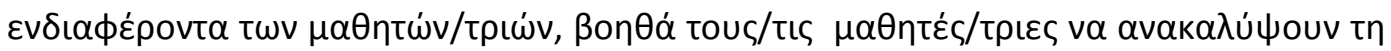

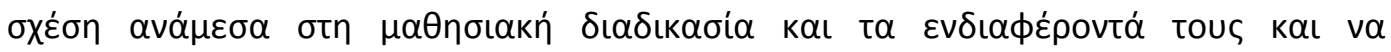

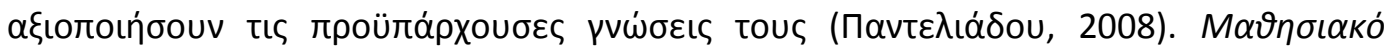

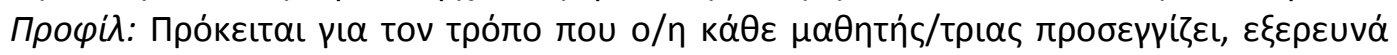

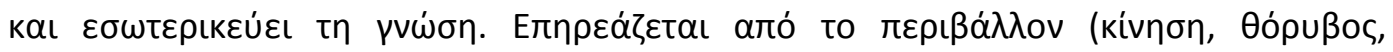

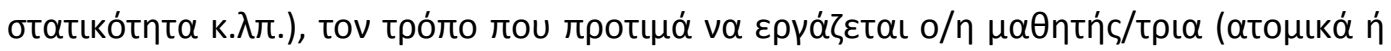

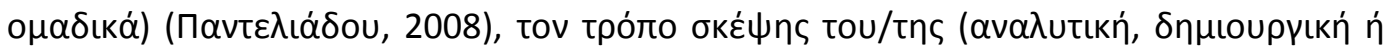

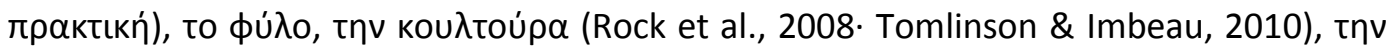

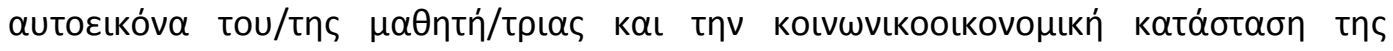

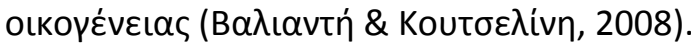

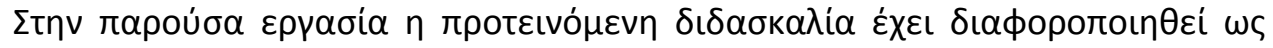

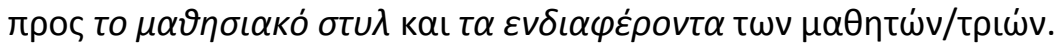

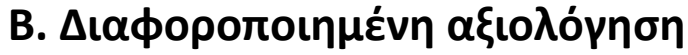

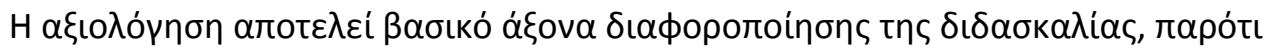

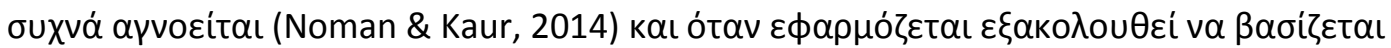

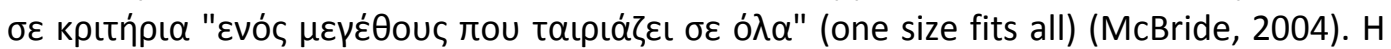

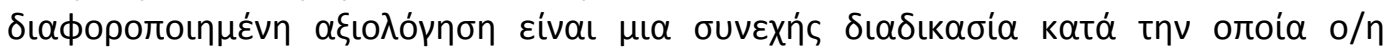

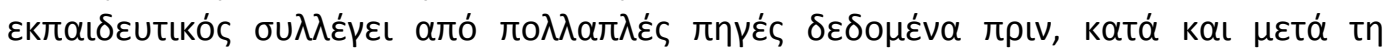

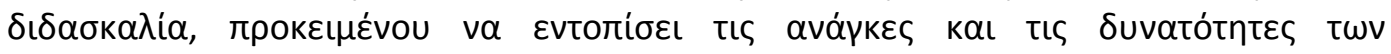

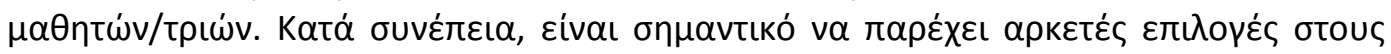

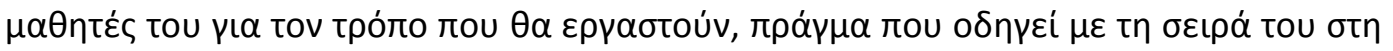

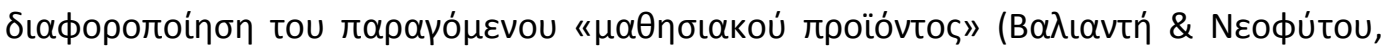

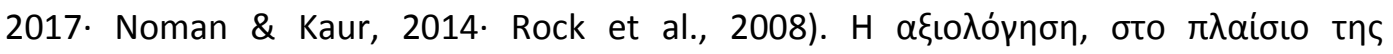

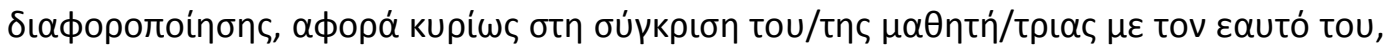

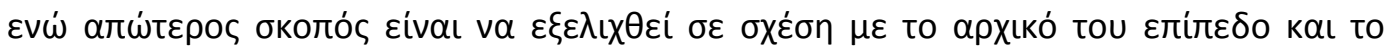

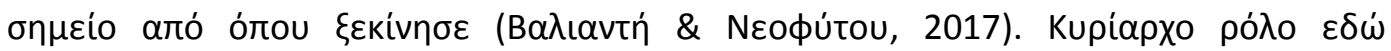

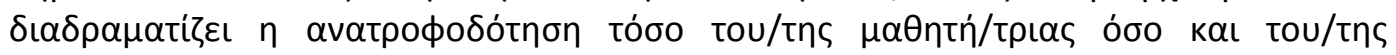

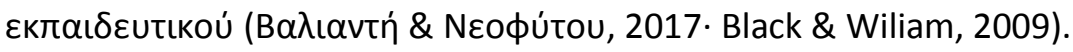

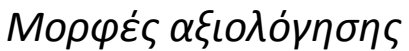

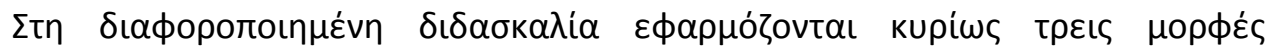

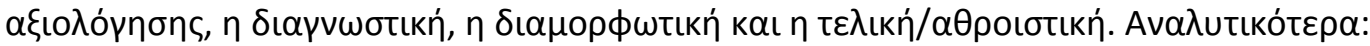

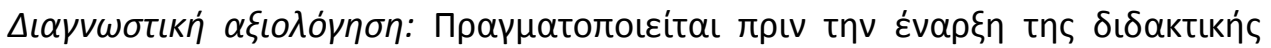

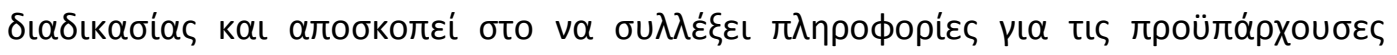

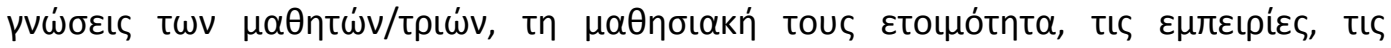

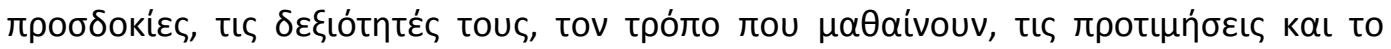

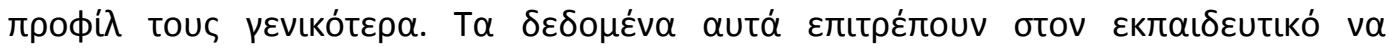

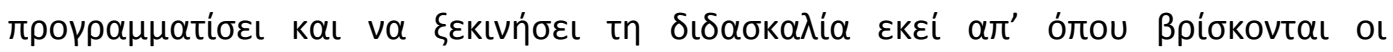

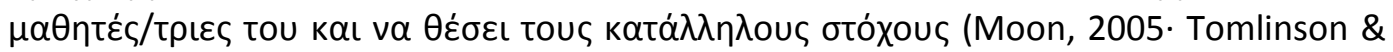




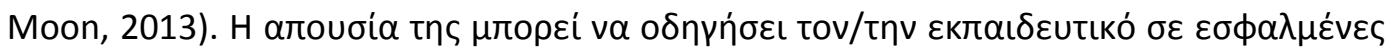

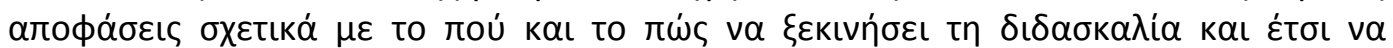

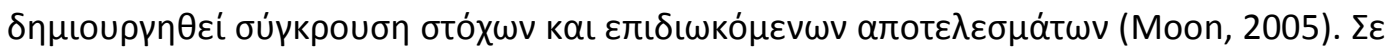

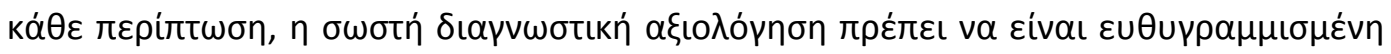

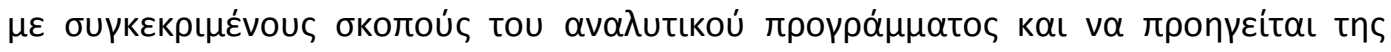

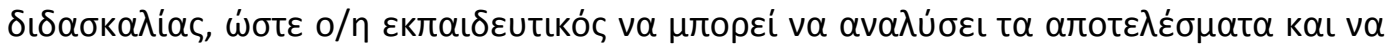

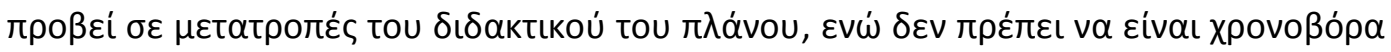
(Moon, 2005).

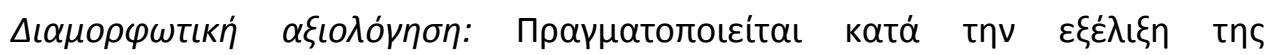

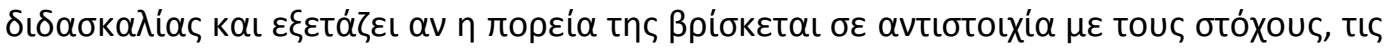

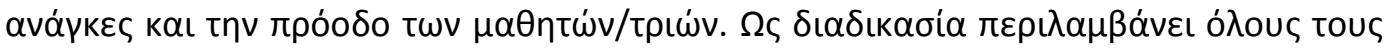

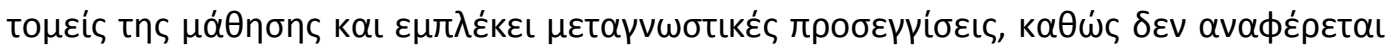

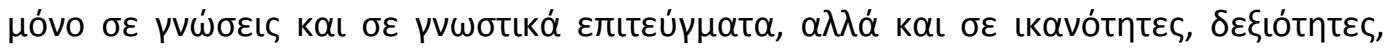

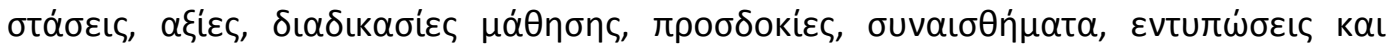

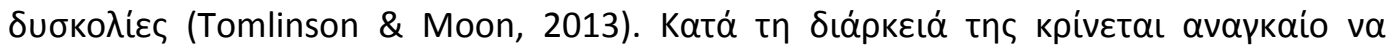

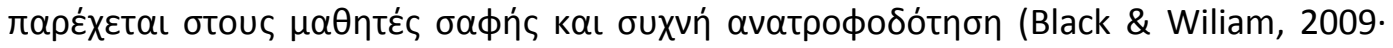

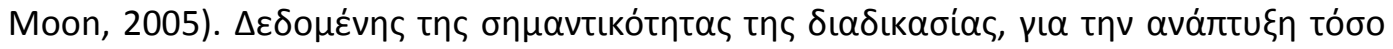

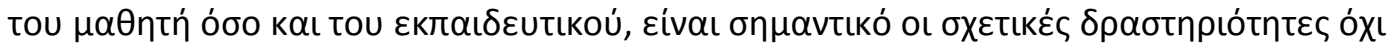

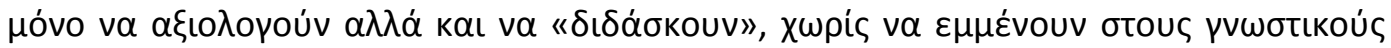

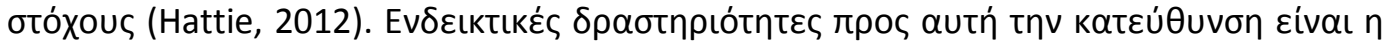

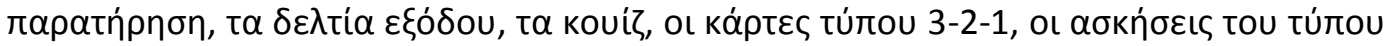

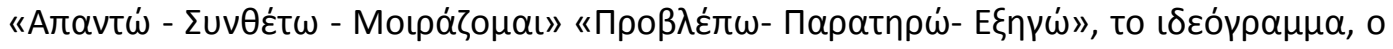

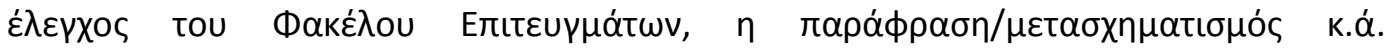

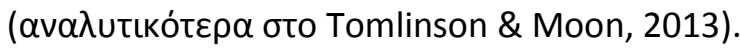

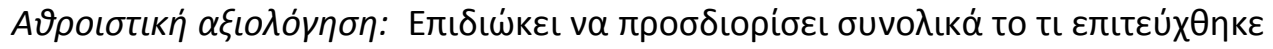

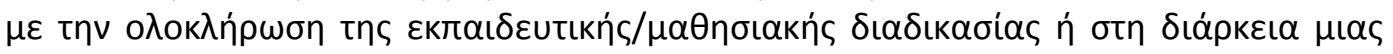

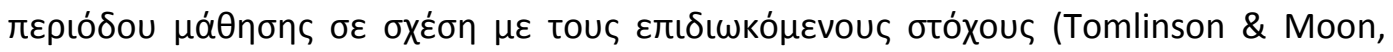

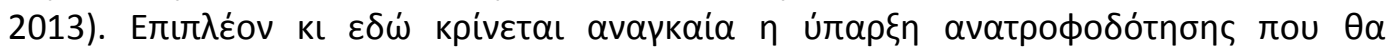

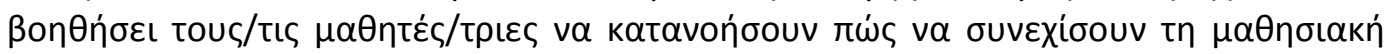

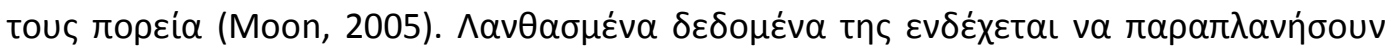

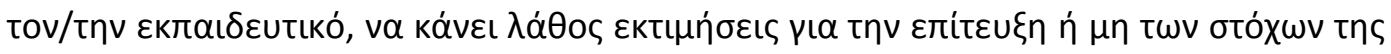

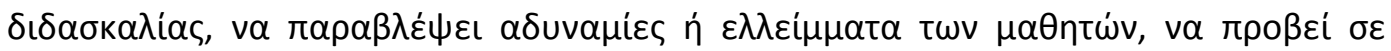

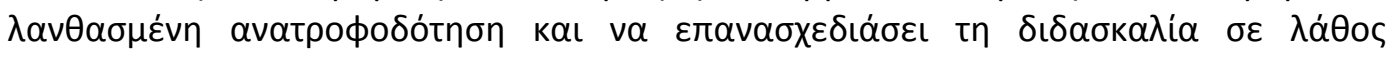

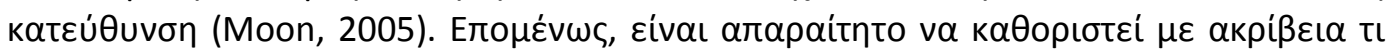

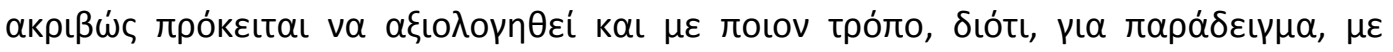

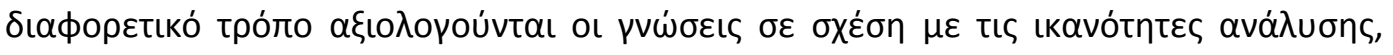

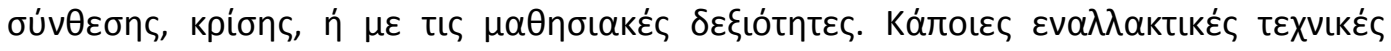

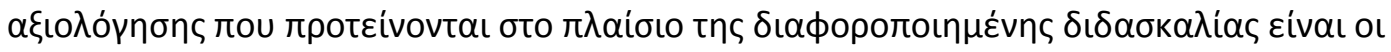

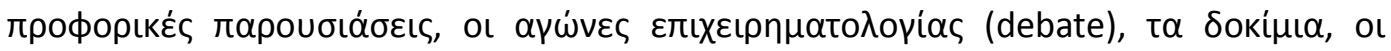

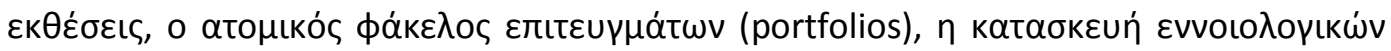

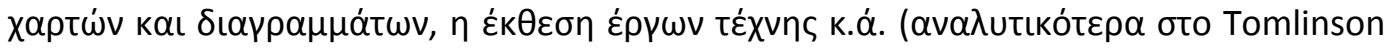
\& Moon, 2013).

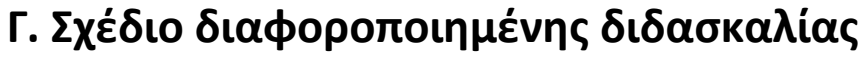

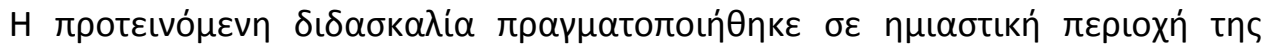

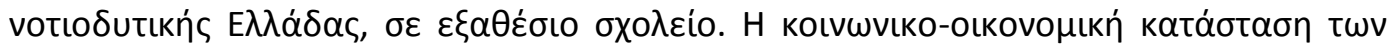




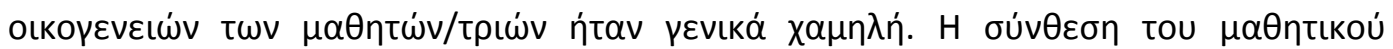

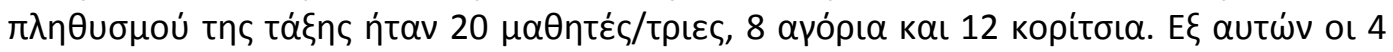

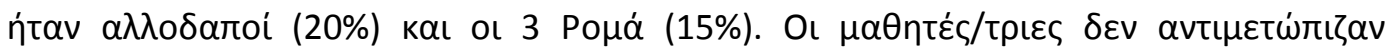

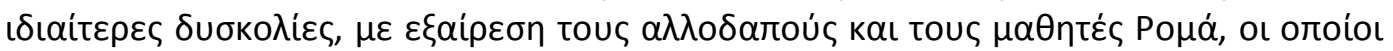

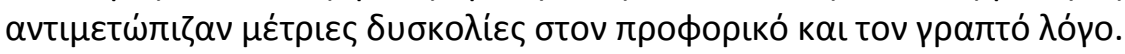

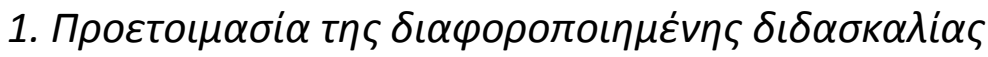

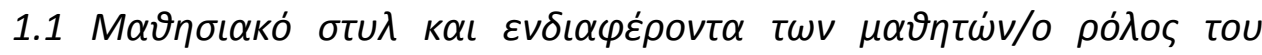
$\delta \alpha \sigma \kappa \alpha \dot{\lambda} \circ u$

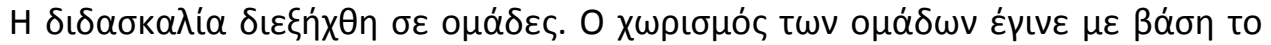

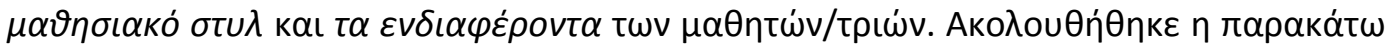

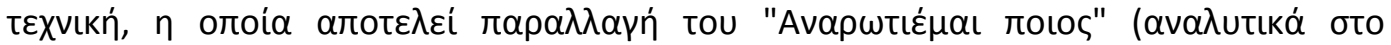

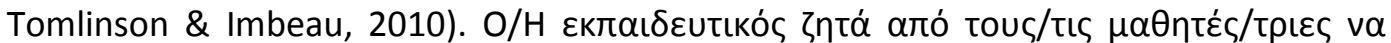

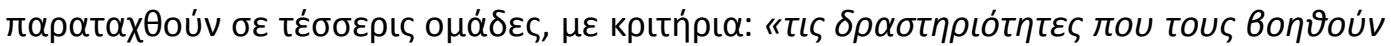

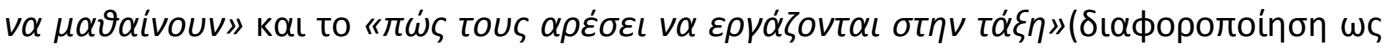

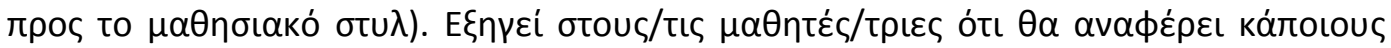

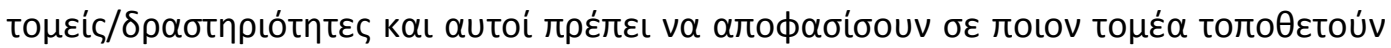

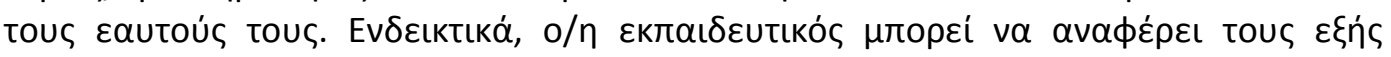

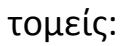

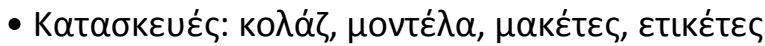

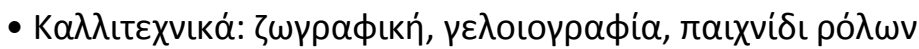

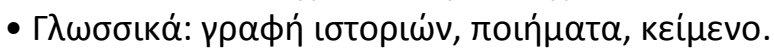

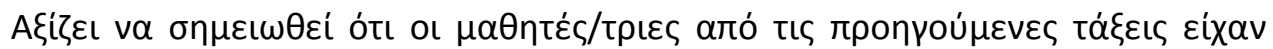

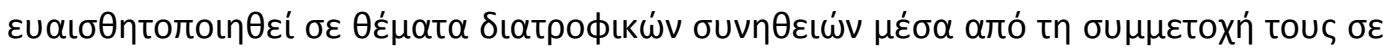

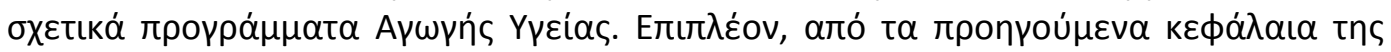

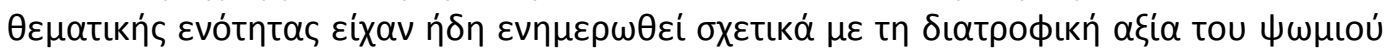

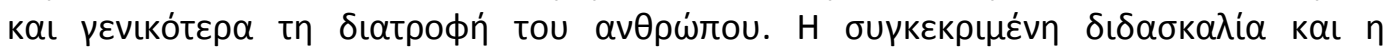

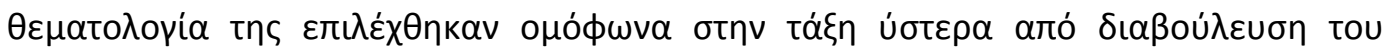

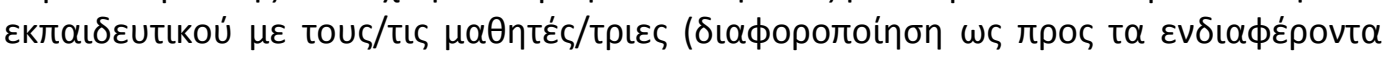
$\tau \omega v \mu \alpha \theta \eta \tau \omega \dot{v} / \tau \rho เ \omega \dot{v})$.

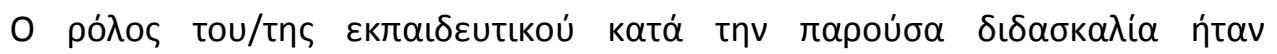

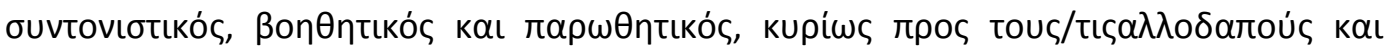

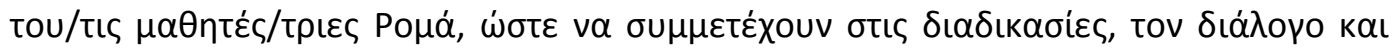

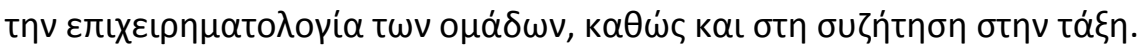

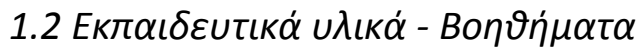

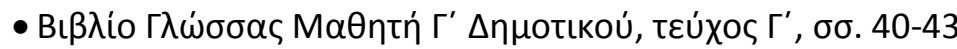

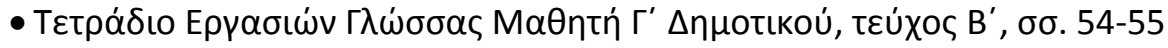

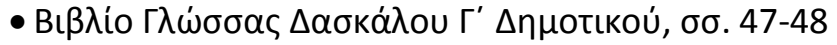

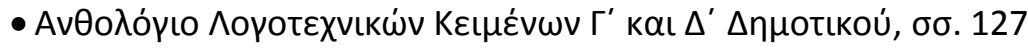

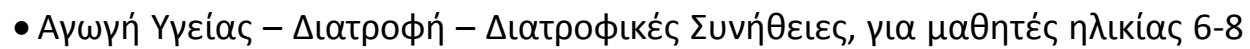

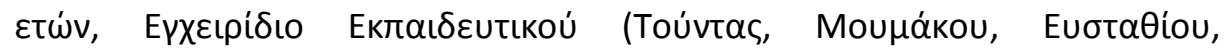

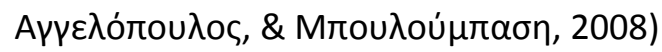




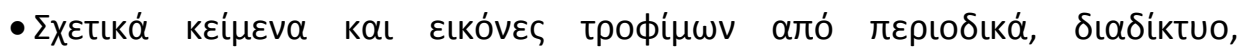

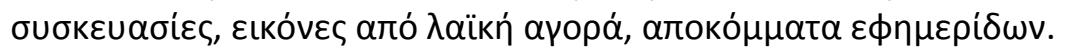

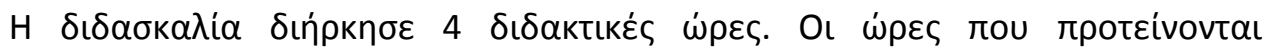

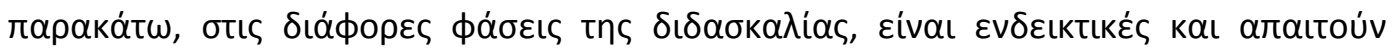

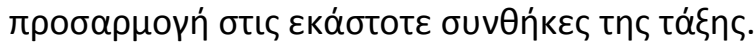

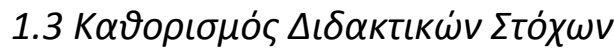

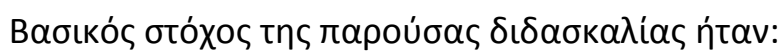

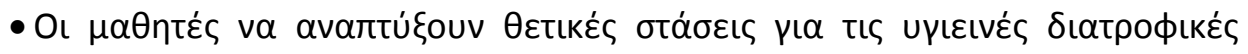

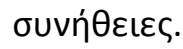

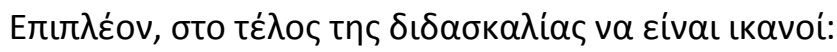

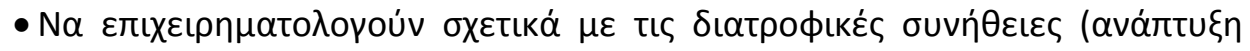

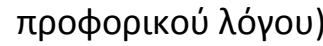

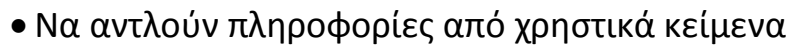

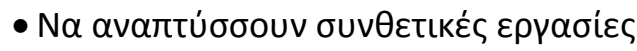

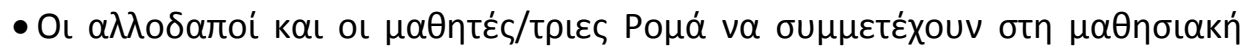

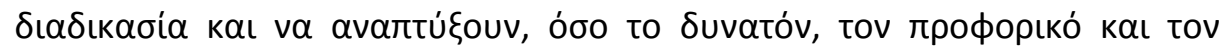

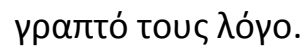

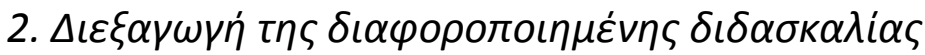

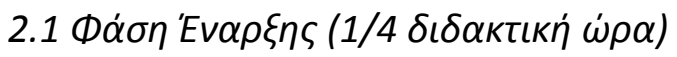

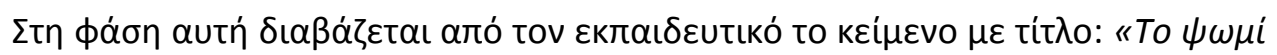

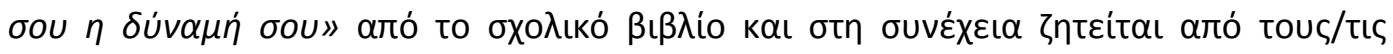

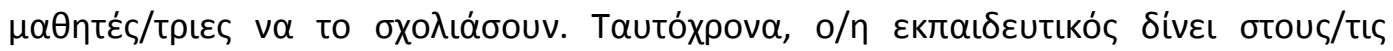

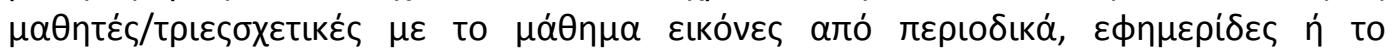

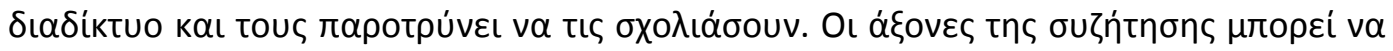

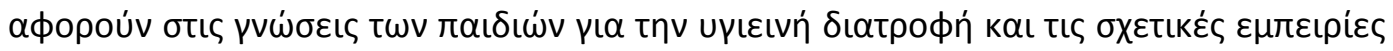

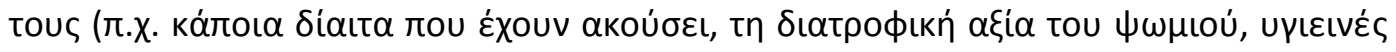

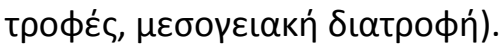

\section{2 Фর்}

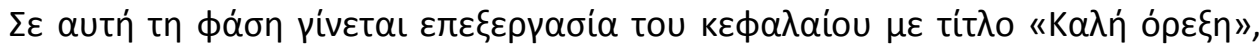

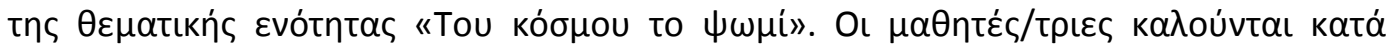

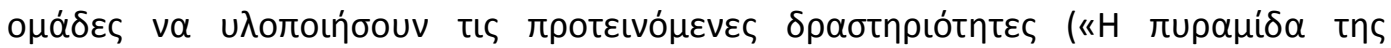

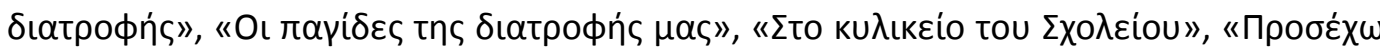

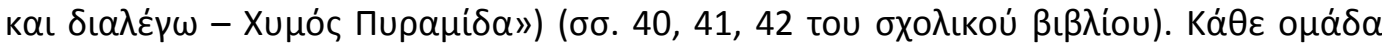

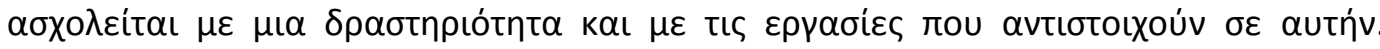

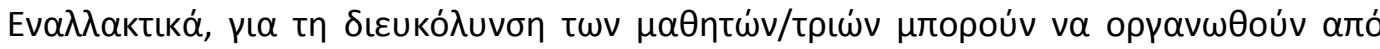

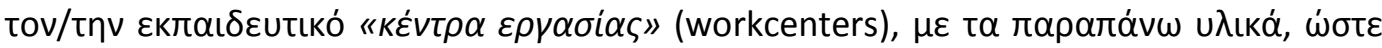

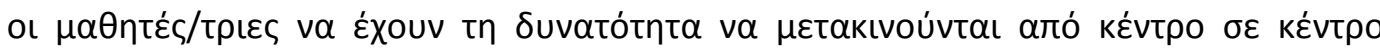

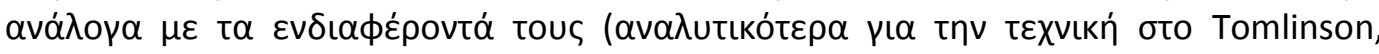
1999). 


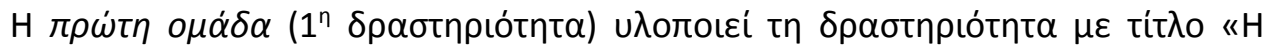

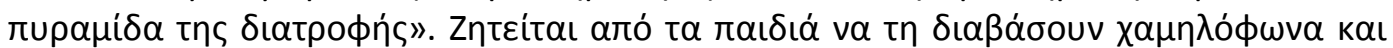

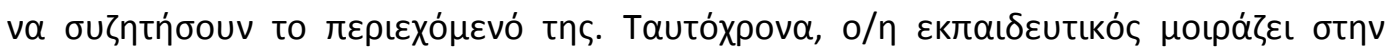

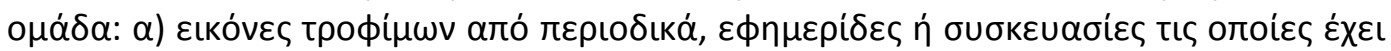

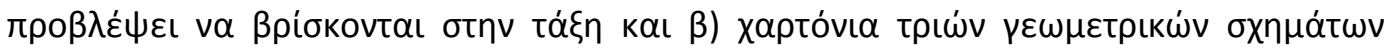

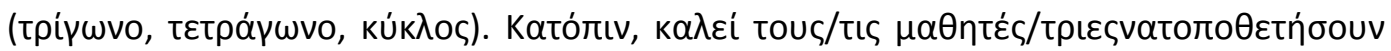

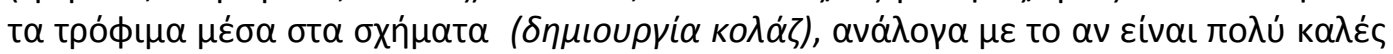

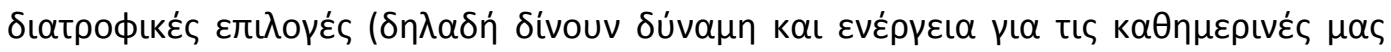

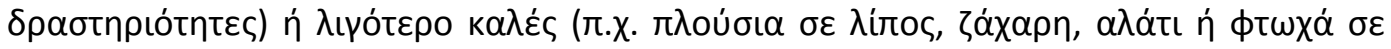

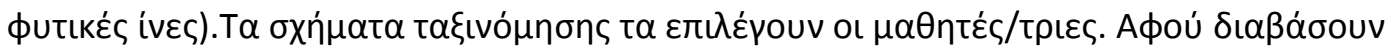

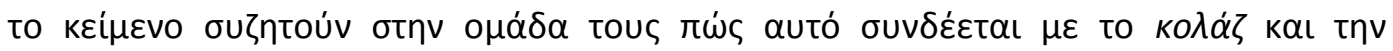

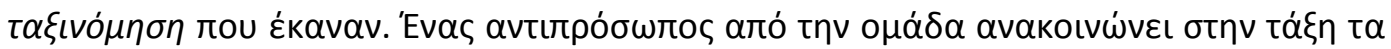

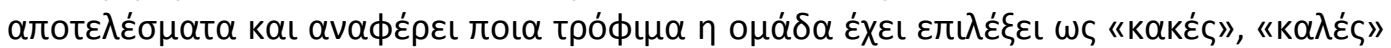

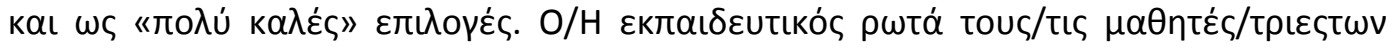

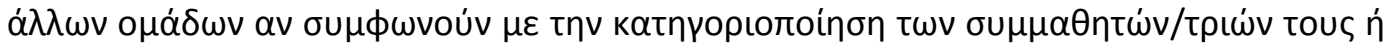

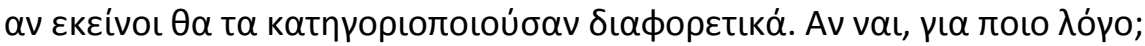

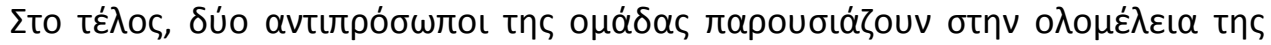

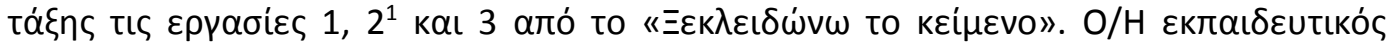

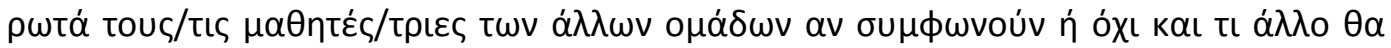

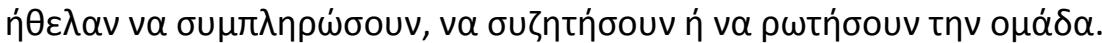

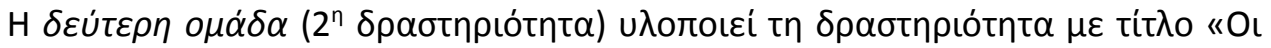

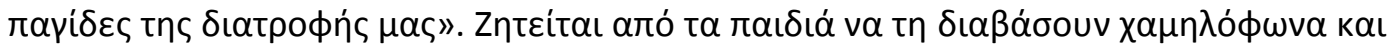

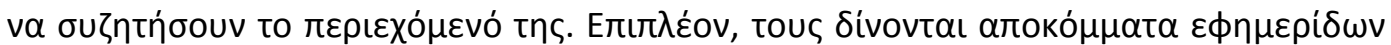

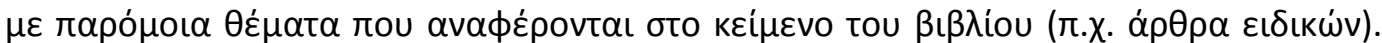

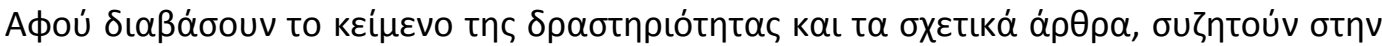

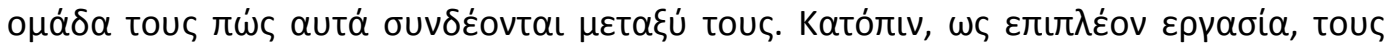

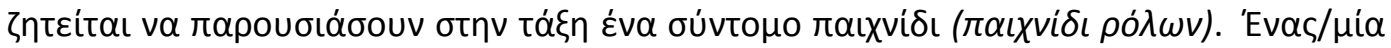

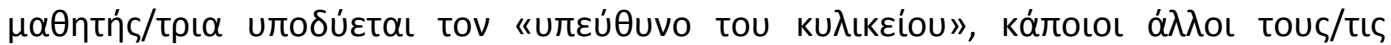

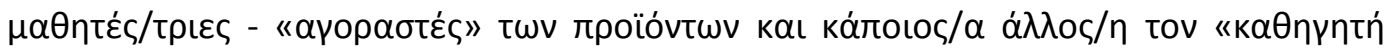

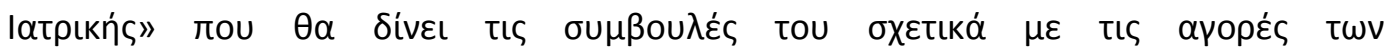

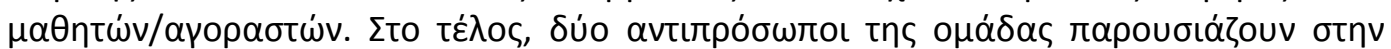
о

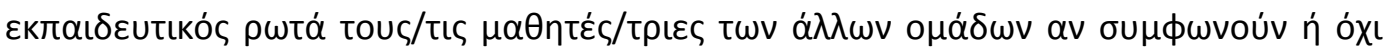

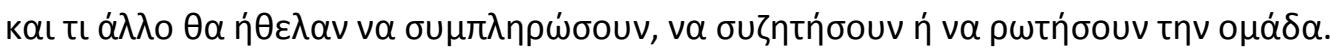

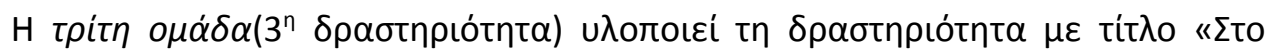
кu

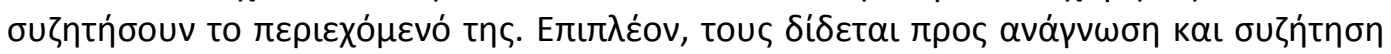

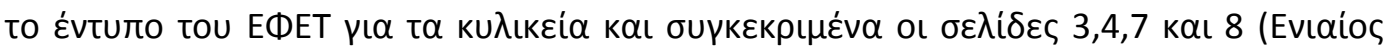

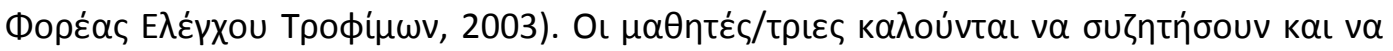

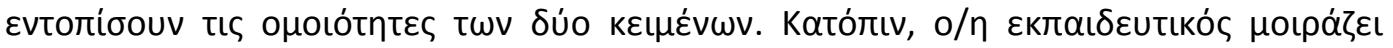

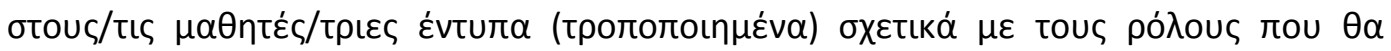

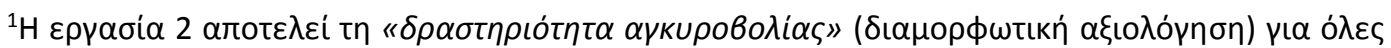

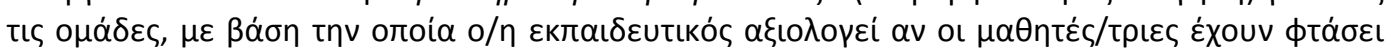

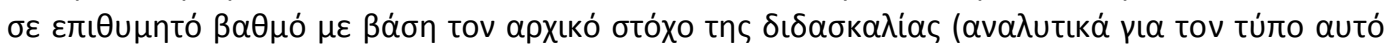

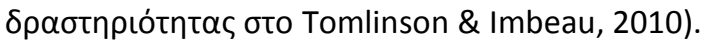




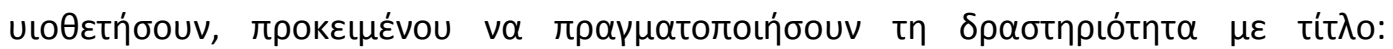

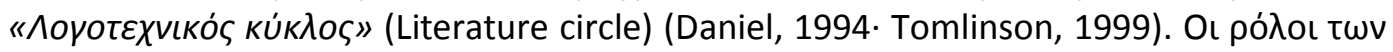

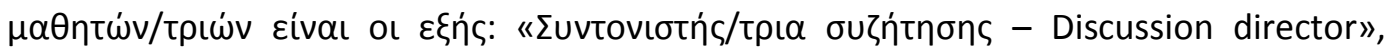

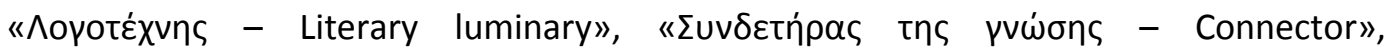

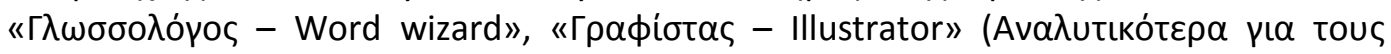

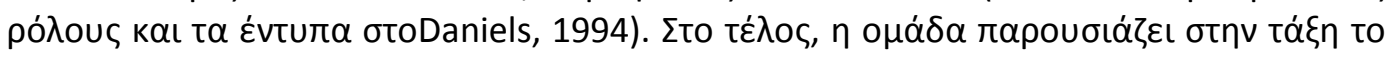

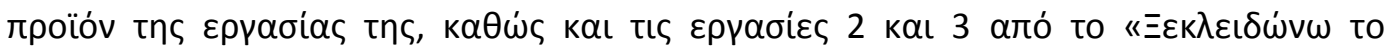

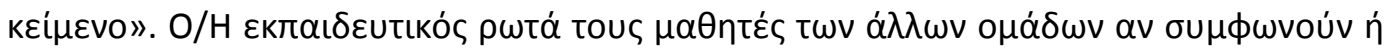

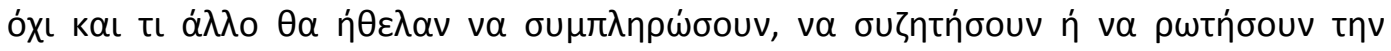

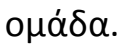

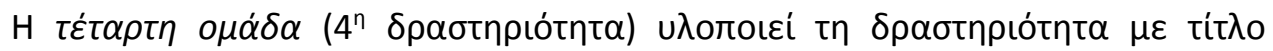

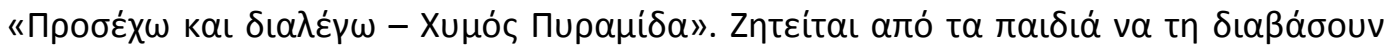

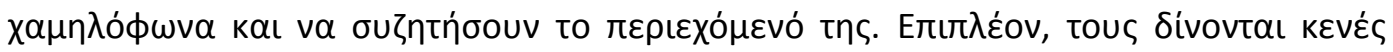

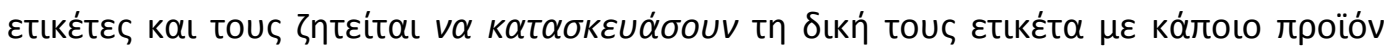

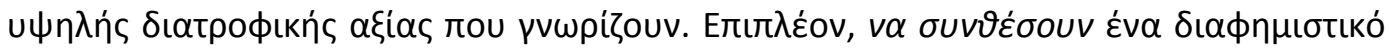

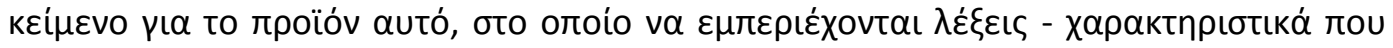

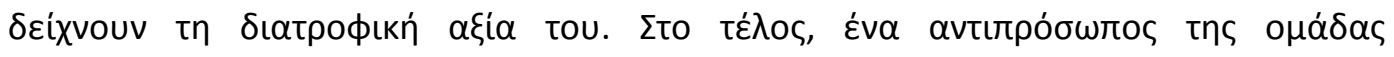

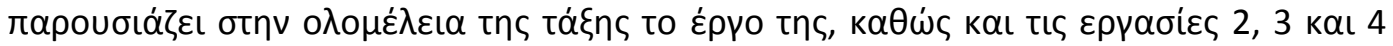

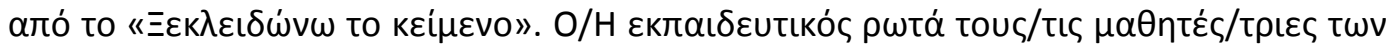

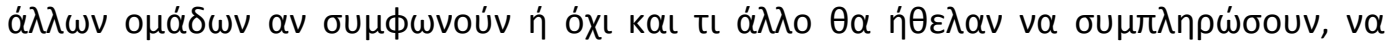

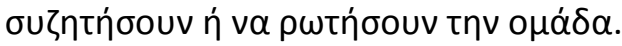

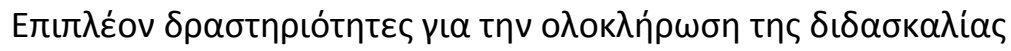

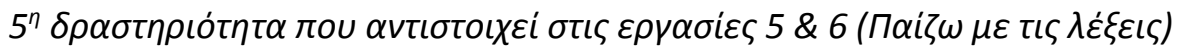

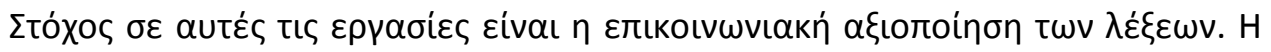

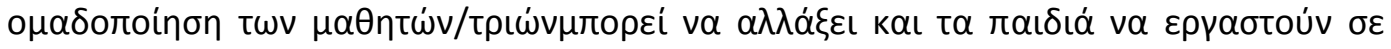

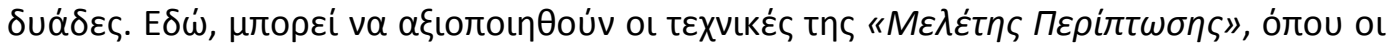

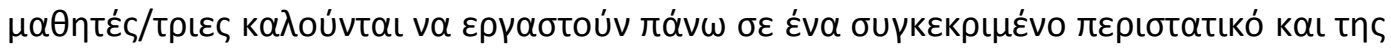

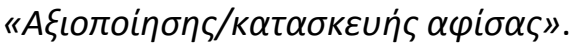

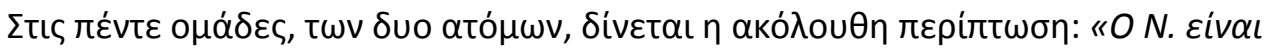

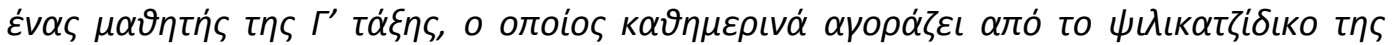

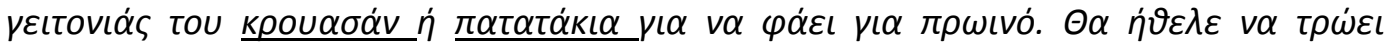

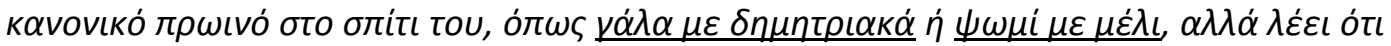

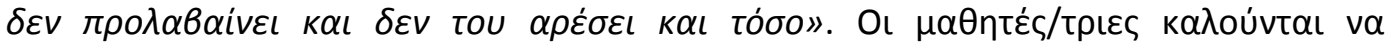

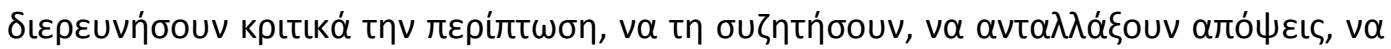

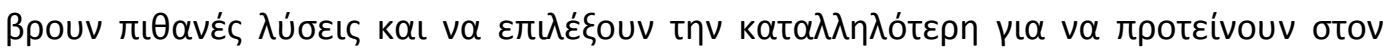

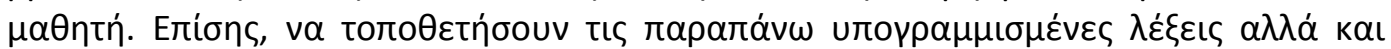

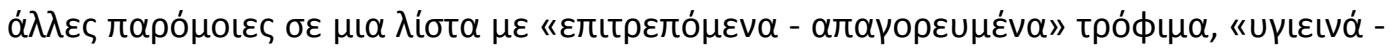

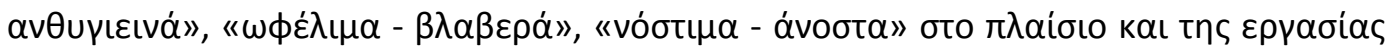
5 tou $\sigma \chi 0 \lambda$ เкоú $\beta$ เ $\beta$ íou.

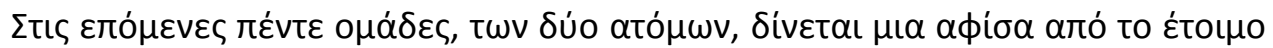

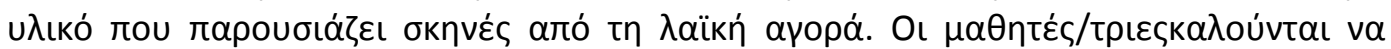

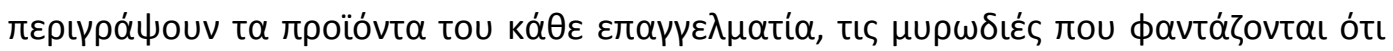

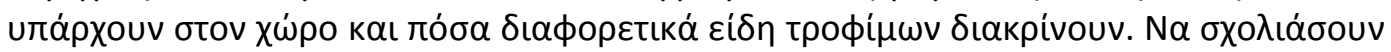

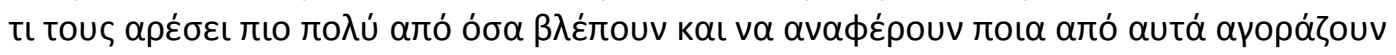




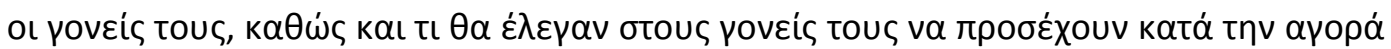

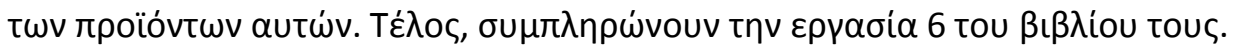

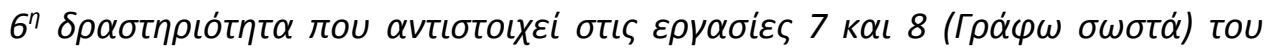

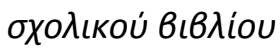

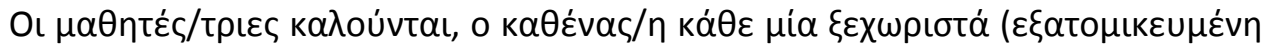

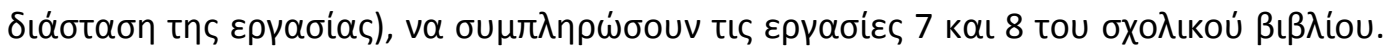

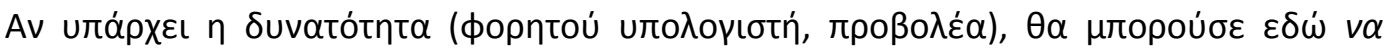

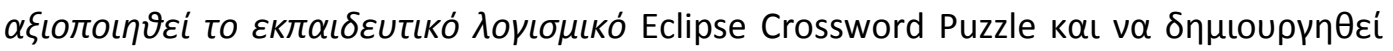

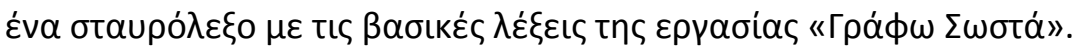

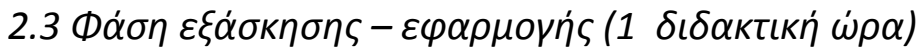

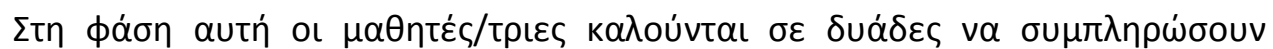

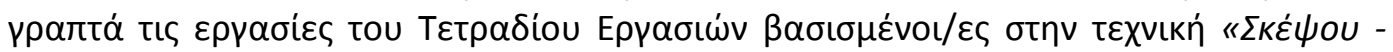

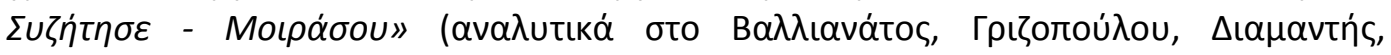

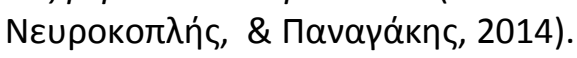

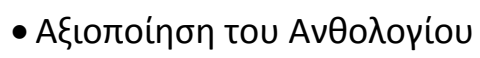

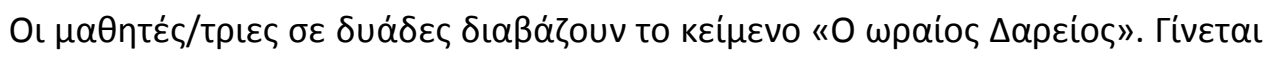

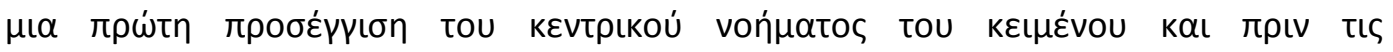

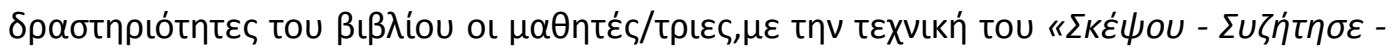

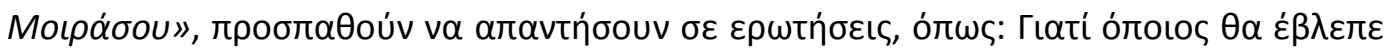

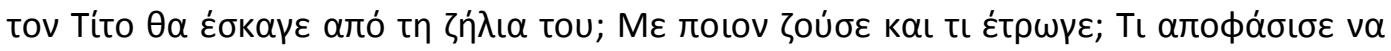

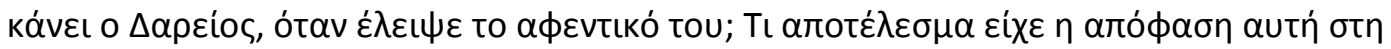

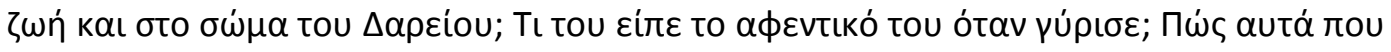

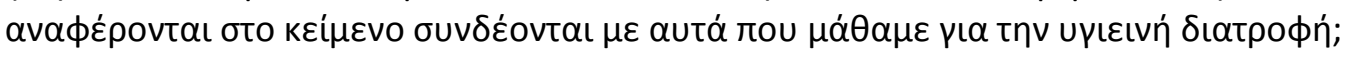

- 'Aбкпоп тúrou 3-2 - 1 (Tomlinson \& Moon, 2013)

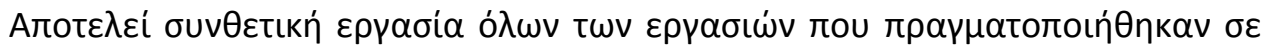

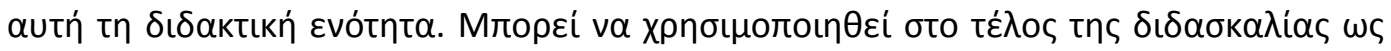

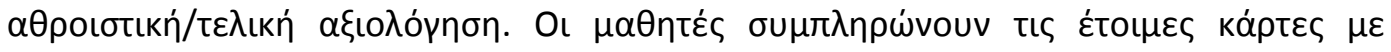

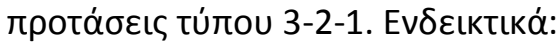

$\sum \eta \mu \varepsilon เ \omega \dot{v} \omega$ :

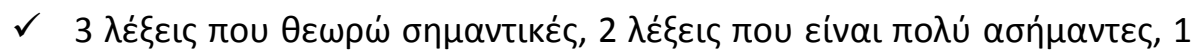

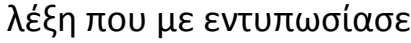

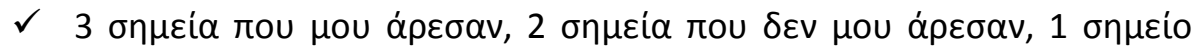

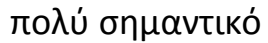

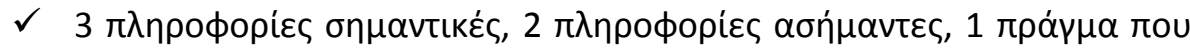

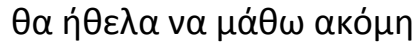

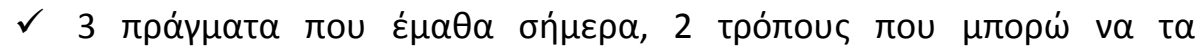

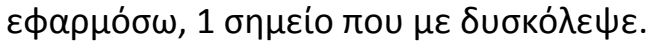

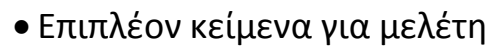

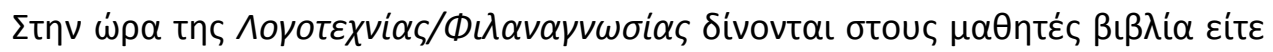

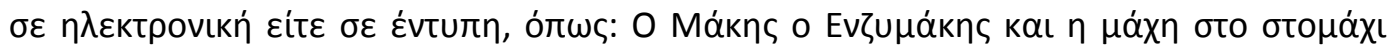




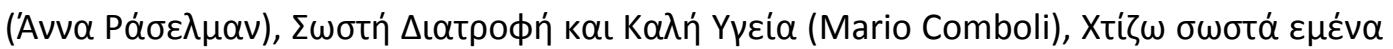

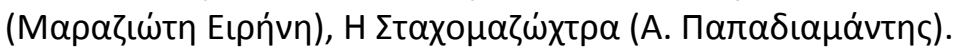

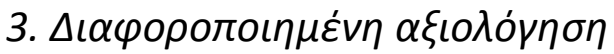

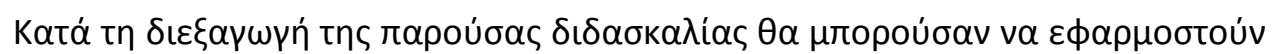

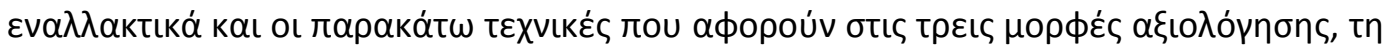

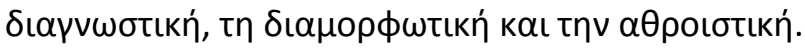

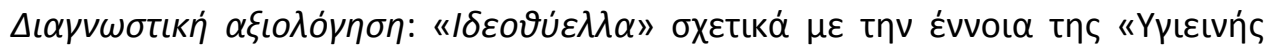
$\Delta$ เатрофńৎ».

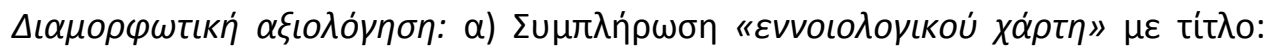

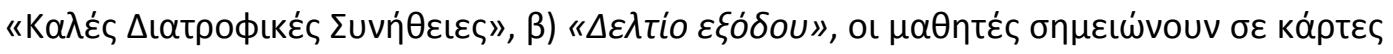

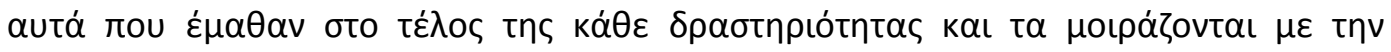

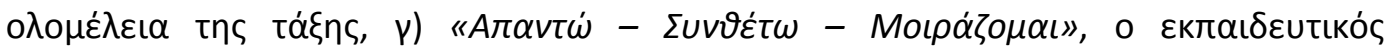

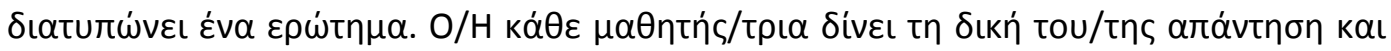

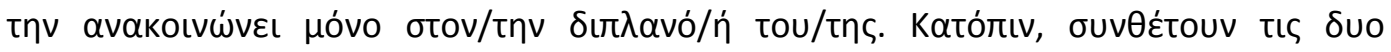

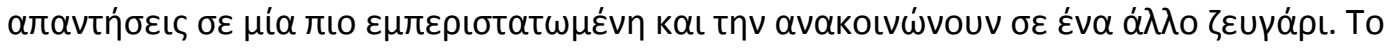

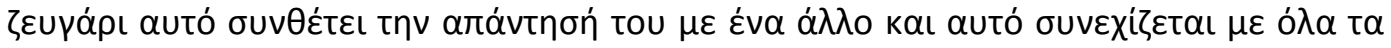

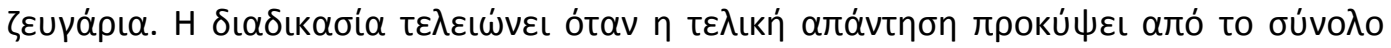

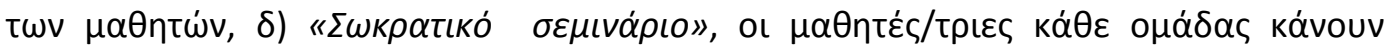

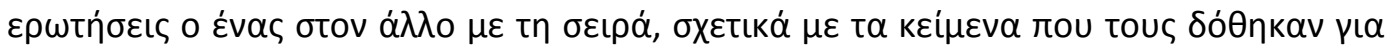
$\varepsilon \pi \varepsilon \xi \varepsilon \rho \gamma \alpha \sigma i \alpha$.

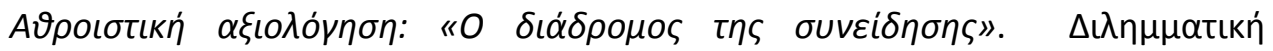

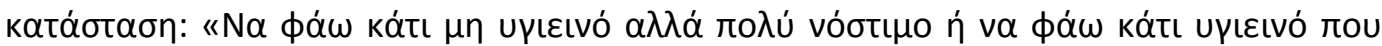

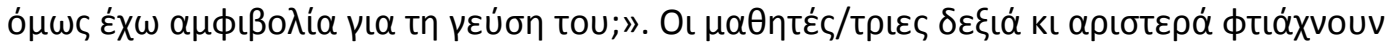

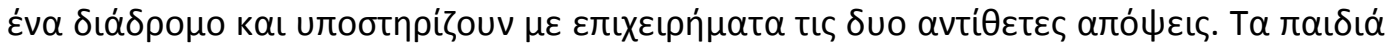

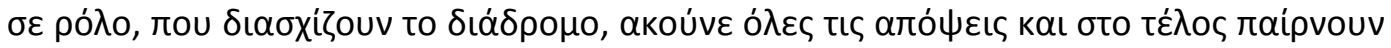

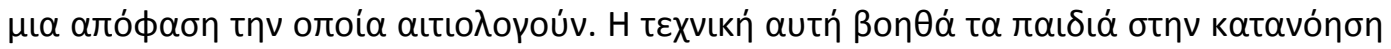

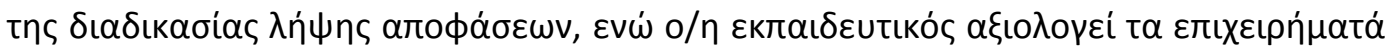

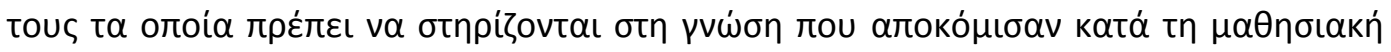

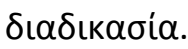

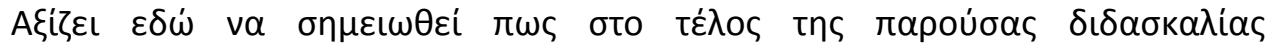

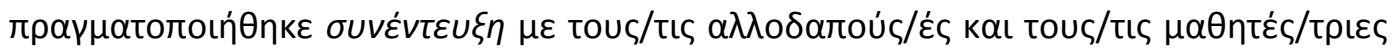

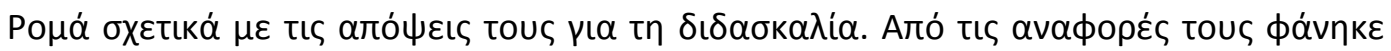

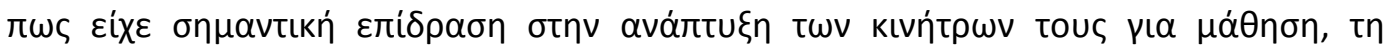

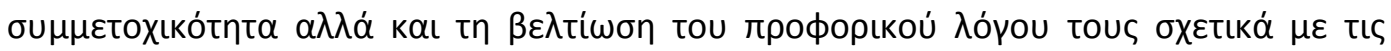

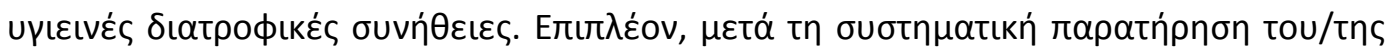

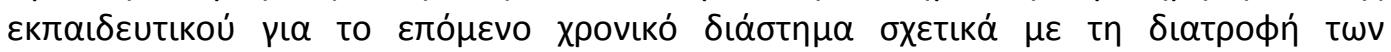

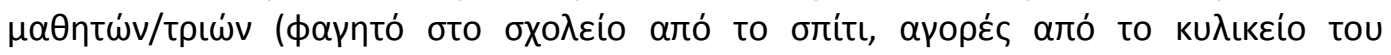

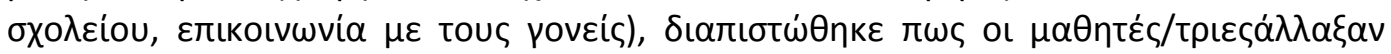

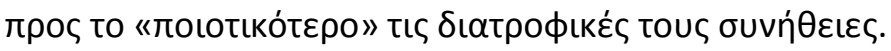

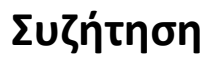

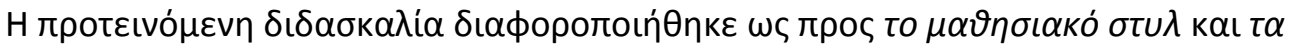

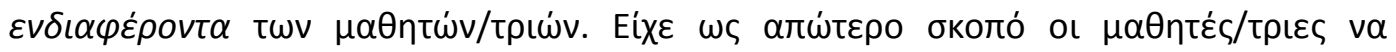




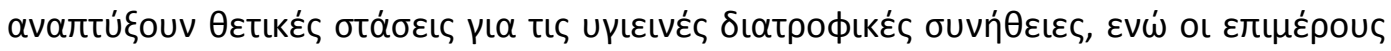

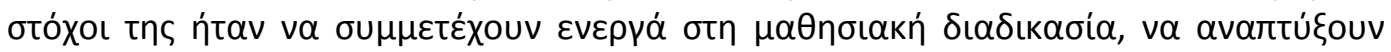

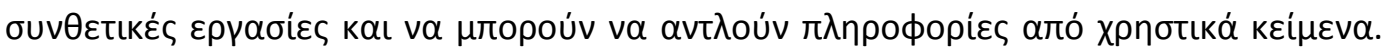

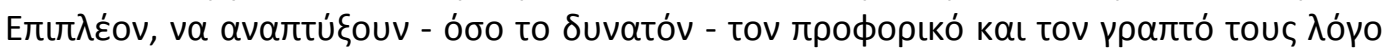

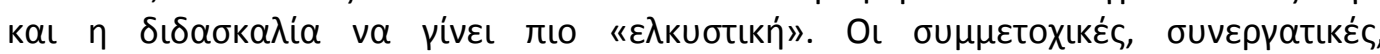

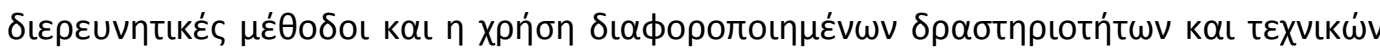

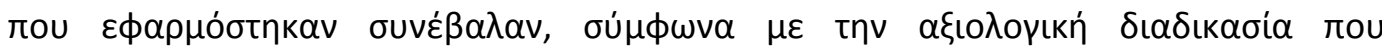

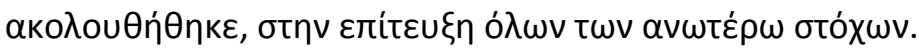

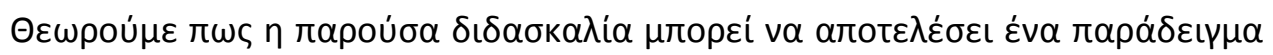

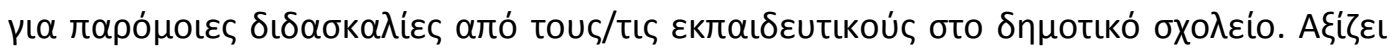

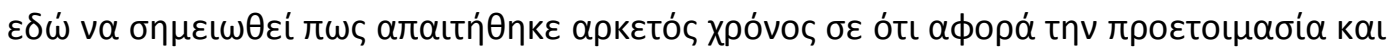

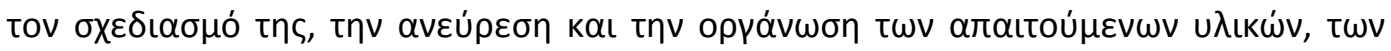

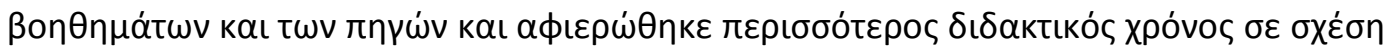

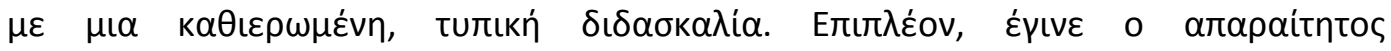

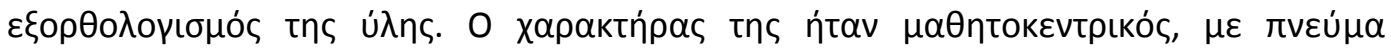

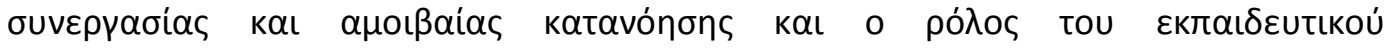

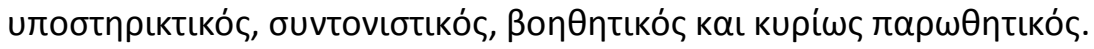

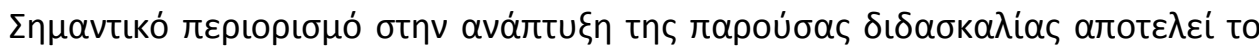

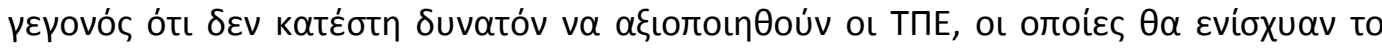

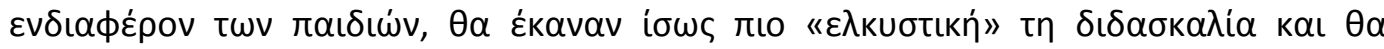

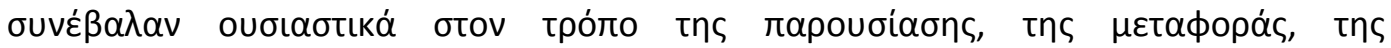

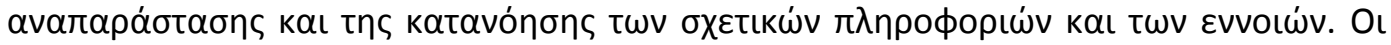

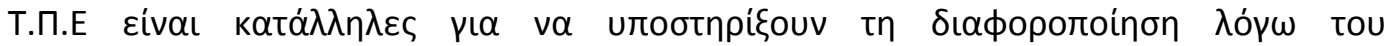

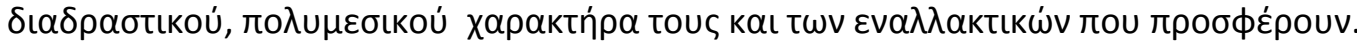

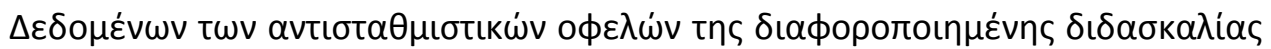

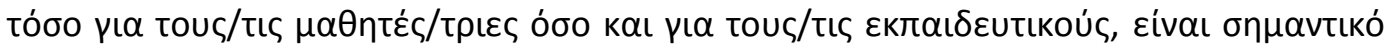

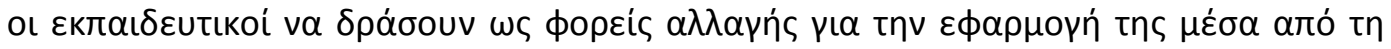

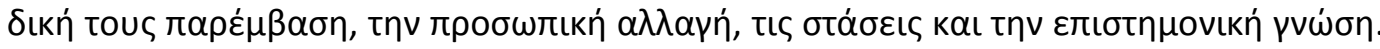

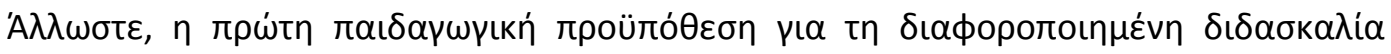

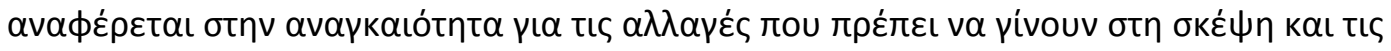

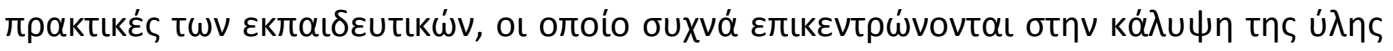

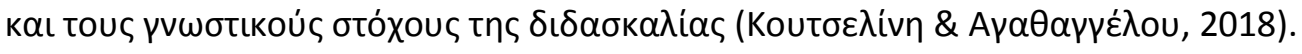

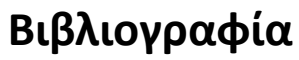

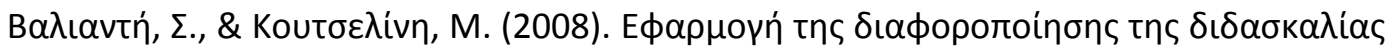

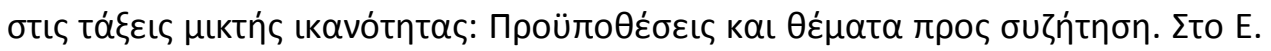

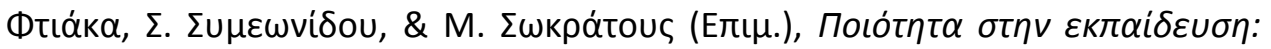

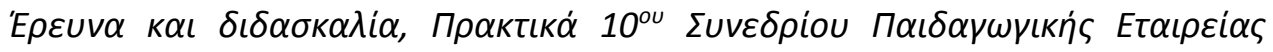

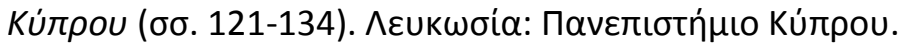

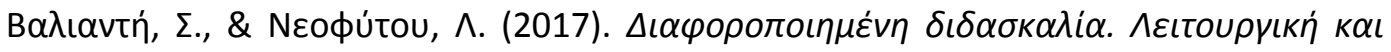

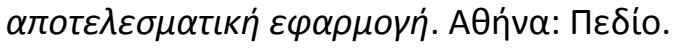




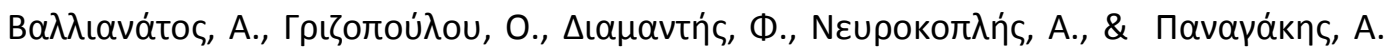

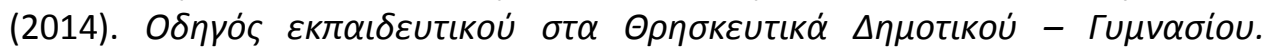

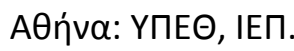

Bearne, E. (1996). Differentiation and diversity in the primary school. London: Routledge.

Black, P., \& Wiliam, D. (2009). Developing the theory of formative assessment. Educational Assessment, Evaluation and Accountability, 21(1), 5-31.

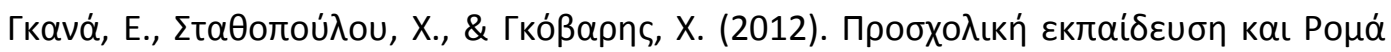

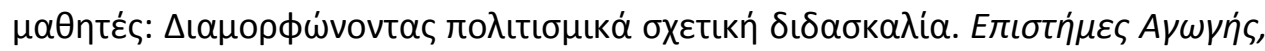
2, 175-190.

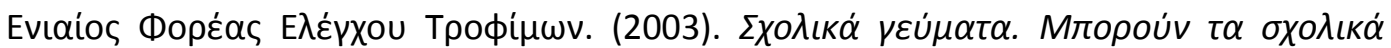

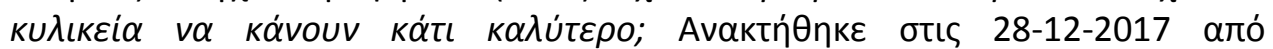
http://www.efet.gr/portal/page/portal/efetnew/enterprises/hygiene guides?pa $\mathrm{r}=\mathrm{ENTERPRISE}$

Earl, L. M. (2012). Assessment as learning: Using classroom assessment to maximize student learning. Thousand Oaks, CA: Corwin Press.

Hart, S. (1992). Differentiation-Way forward of retreat? British Journal of Special Education, 19(1), 10-12.

Daniels, H. (1994). Literature circles: Voice and choice in the student-centered classroom. York, ME: Stenhouse Publishers.

Hattie, J. (2012). Know thy impact. Educational Leadership, 1(70), 18-23.

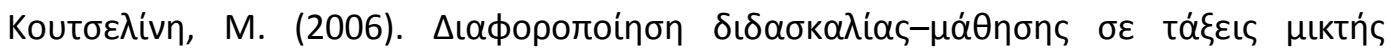

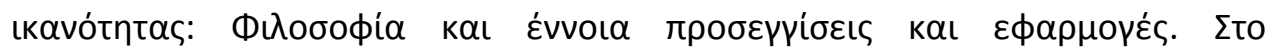

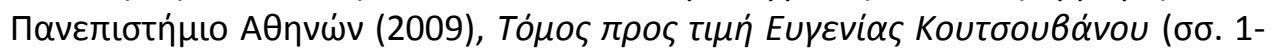

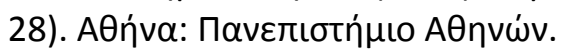

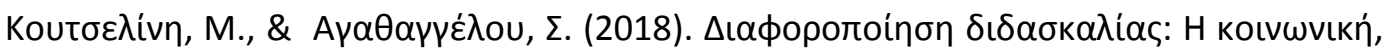

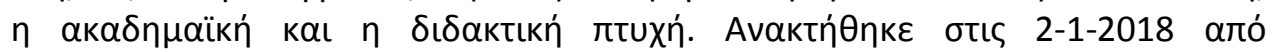
https://www.ucy.ac.cy/release/documents/Publications/Greek/KoutseliniAgath angelou DifferentiationofTeachingActionResearch.pdf

McBride, B. (2004). Data-driven instructional methods: "One strategy fits all" doesn't work in real classrooms. T.H.E Journal, 31(11), 38-40.

Moon, T. R. (2005). The role of assessment in differentiation. Theory Into Practice, 4(3), 226-233.

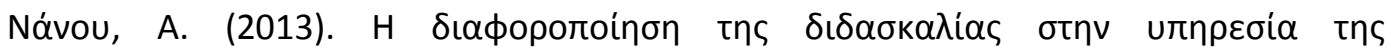

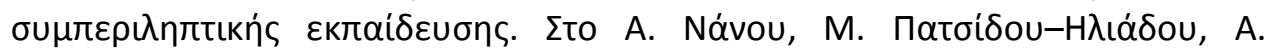

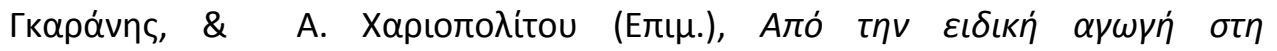

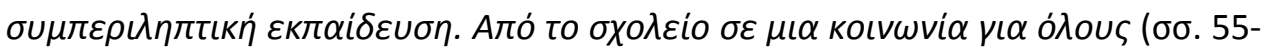

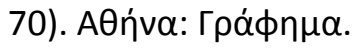

Noman, M., \& Kaur, A. (2014). Differentiated assessment: A new paradigm in assessment practices for diverse learners. International Journal of Education and Applied Sciences, 1(4), 141-146. 


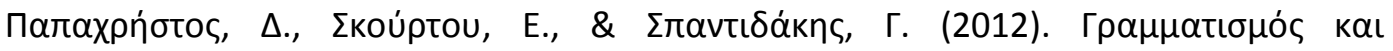
$\varepsilon \kappa \pi \alpha i \delta \varepsilon v \sigma \sigma \eta \eta$

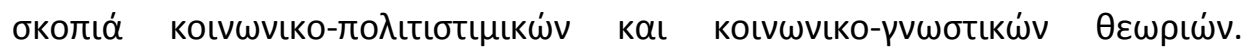

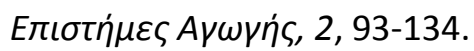

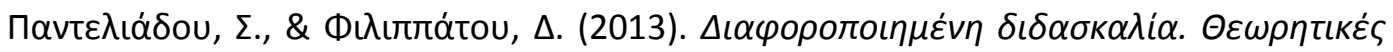

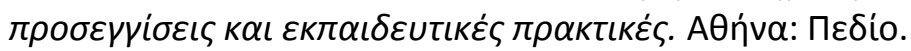

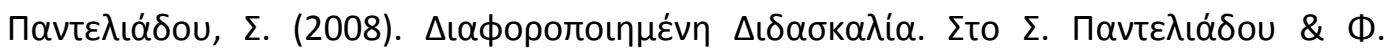

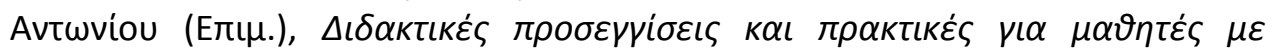

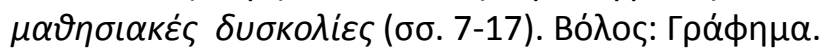

Rock, M. L., Gregg, M., Ellis, E., \& Gable, R. A. (2008). REACH: A framework for differentiating classroom instruction. Preventing School Failure: Alternative Education for Children and Youth, 52(2), 31-47.

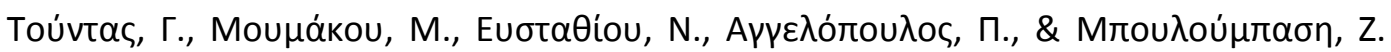

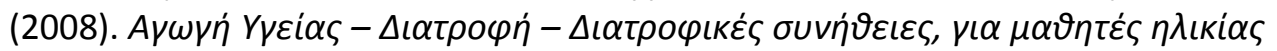

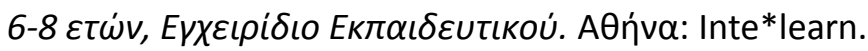

Tomlinson, C. A. (1999). The differentiated classroom: Responding to the needs of all learners. Alexandria, VA: ASCD.

Tomlinson, C. A. (2001). How to differentiate instruction in mixed-ability classrooms $\left(2^{\text {nd }}\right.$ Ed.). Alexandria, VA: ASCD.

Tomlinson, C. A., \& Imbeau, M. B. (2010). Leading and managing a differentiated classroom. Alexandria, VA: ASCD.

Tomlinson, C. A., \& Moon, T. R. (2013). Assessment and student success in a differentiated classroom. Alexandria, VA: ASCD.

Tomlinson, C. A., Brighton, C., Hertberg, H., Callahan, C. M., Moon, T. R., Brimijoin, K., ... \& Reynolds, T. (2003). Differentiating instruction in response to student readiness, interest, and learning profile in academically diverse classrooms: A review of literature. Journal for the Education of the Gifted, 27(2-3), 119-145.

Valiandes, S. (2015). Evaluating the impact of differentiated instruction on literacy and reading in mixed ability classrooms: Quality and equity dimensions of education effectiveness. Studies in Educational Evaluation, 45, 17-26. 